\title{
Estimates of climate change in Southern Europe derived from dynamical climate model output
}

\author{
U. Cubasch ${ }^{1, *}$, H. von Storch ${ }^{2}$, J. Waszkewitz ${ }^{1}$, E. Zorita ${ }^{2}$ \\ ${ }^{1}$ Deutsches Klimarechenzentrum GmbH, Bundesstr. 55, D-20146 Hamburg, Germany \\ ${ }^{2}$ GKSS, Max-Planck-Straße, D-21502 Geesthacht, Germany
}

\begin{abstract}
Three methods of downscaling are applied to climate change experiments to obtain regional climate information for Spain and the region designated as 'Southern Europe' by the Intergovernmental Panel on Climate Change (IPCC). The first method (direct interpolation of the grid points nearest the region analysed) gives a poor representation of the local climate. Its estimate of climate change simulated by different climate models is inconsistent. The success of the second method (timeslice), which uses a dynamical model to obtain the regional information, strongly depends on the horizontal resolution of the dynamical model. It provides the most reliable assessment of the regional climate, with the highest resolution. However, the computational expense of this high resolution limits the sample size. The third method (statistical downscaling) is an inexpensive tool for obtaining information on a regional scale. The problem is that this approach requires observational data sets to train the model. This limits the application of this method to well-observed quantities and regions. Both the time-slice and the statistical models indicate a lengthening of dry spells over Spain under $\mathrm{CO}_{2}$ doubling conditions.
\end{abstract}

KEY WORDS: Downscaling $\cdot$ Regional climate change $\cdot$ Southern Europe

\section{INTRODUCTION}

Southern Europe has been perceived to be particularly vulnerable to climate change. It lies on the border between the temperate climate of the mid-latitudes and the desert conditions of the subtropical high pressure belt. The southern edge of Southern Europe is less than $100 \mathrm{~km}$ away from the Sahara. The climate of Southern Europe is influenced by the Mediterranean Sea to the south, and by the North Atlantic to the west. At the northern extremity, it is sheltered from the direct influences of northerly winds by the Pyrenees and the Alps. General circulation models (GCMs) have so far been too coarse to resolve this geographically well-defined region. One has therefore to resort to either statistical or dynamical methods to downscale the large-scale information to the regional scale and to resolve the important geographically induced features.

A number of studies have been carried out to create a connection between climate change at the large

·E-mail: cubasch@dkrz.de scale, as predicted by dynamical models, and at the regional scale. The most straightforward approach is linear (or more sophisticated methods of) interpolation between large-scale grid points closest to the region to infer the regional scale. This method has attracted a lot of criticism, since it was felt that the model resolution was too coarse and the model performance was too poor to allow for interpretation of the results (Wigley et al. 1990, Grotch \& McCracken 1991, von Storch et al. 1993). Nevertheless, this approach is widely undertaken because it is easy and fast to apply.

To overcome the problems with direct interpolation, an approach termed 'downscaling' can be pursued. This approach is based on the understanding that: (1) Climate models are successful in simulating the largescale state of the atmosphere, even though they fail to reproduce the regional and local details (Grotch \& McCracken 1991, von Storch 1995). These details are of little or no importance for the large-scale state of the atmosphere, which is mainly determined as the result of planetary-scale forcing (solar radiation) and the planetary-scale pattern of orography and land-sea dis- 
tribution. (2) The regional facets of the atmospheric state are the result of an interplay between the largescale state and the regional details such as topography, land-sea distribution, vegetation and the like.

Thus, the large-scale information provided by standard coarse-grid GCMs may be postprocessed together with the regional information to specify the regional details of the present climate and its sensitivity to changes in atmospheric composition or other 'external' anomalies. This postprocessing can be done in different ways:

(1) In time-slice experiments, the distributions of seaice and of the sea-surface temperature derived from transient coarse-resolution climate change experiments are used as lower boundary conditions for simple simulations with high-resolution models of the atmosphere under increased $\mathrm{CO}_{2}$ concentration. With such models, detailed structures such as hurricanes can be simulated. Postprocessing of the climate change. scenario has revealed that neither the frequency nor the intensity of hurricanes is likely to increase when $\mathrm{CO}_{2}$ concentrations double (Bengtsson et al. 1994b). Such models can be run for a long time to give a sufficiently long statistical sample (Cubasch et al. 1995b). Compared to nested regional model simulations, timeslice integrations have the advantage that their domain is global, i.e. several regions can be analysed at the same time with identical circulation conditions. Furthermore, in time-slice simulations all processes and interactions are calculated on a finer grid, while in a regional model the feedback from the fine scale to the coarse-grid global scale is not calculated.

(2) Regional 'nested' models (Giorgi 1990, Georgi \& Mearns 1991, Mearns et al. 1995) are limited in their spatial domain and are forced with prescribed sea surface temperatures as well as lateral time-dependent atmospheric boundary conditions. Typical spatial domains are of the size of North America. Due to the 1 way coupling, i.e. the coarse-grid model gives information to the regional model but does not receive modified fields from it, problems in the circulation field of the coarse-grid model are fed into (and sometimes amplified by) the regional simulation. The regional model acts as an interpreter of the coarse-grid model (Machenhauer et al. 1996) without having the possibility of (positively) influencing the coarse-grid simulation.

(3) Computationally less demanding approaches exploit empirically derived relationships between fields representative of the large-scale state, such as air pressure, and the local time series, like precipitation. Such statistical approaches can be designed in many different ways, and have been applied to various parameters (see e.g. Bardossy \& Plate 1991. Hewitson \& Crane 1992, von Storch et al. 1993, Gyalistras et al. 1994, Zorita et al. 1995)
(4) A combination of statistical methods and a dynamical model has been successfully applied by Frey-Buness et al. (1995) In this approach, the flow characteristics of a coarse-resolution model are analysed statistically and then fed into a regional-scale dynamical model. Techniques which postprocess large-scale model output by means of dynamical or statistical tools in order to describe aspects of regional or local climate are named 'dynamical downscaling' or 'statistical downscaling', respectively. When applied to infer aspects of regional climate change, both approaches exploit a tacitly made assumption, namely that the parameterizations of dynamical models or the empirical links in statistical models continue to prevail under changed large-scale climate conditions (Matyasovzky et al. 1995).

In the present paper, we will first introduce the climate change experiments on which our study is based (Section 2), then prove the inadequacy of a straightforward interpolation of coarse model results on the regional scale (Section 3 ). We utilize the time-slice method as a means of dynamical downscaling to specify expected climate change for Southern Europe (Section 4) and the analog method as a statistical downscaling approach to specify local changes on the Iberian Peninsula (Section 5).

\section{CLIMATE CHANGE EXPERIMENTS}

Transient experiments are carried out with coupled ocean-atmosphere GCMs (OAGCMs); an OAGCM consists of an atmosphere circulation model (AGCM) coupled to a comprehensive ocean circulation model (OGCM). The models are forced with a gradual increase of $\mathrm{CO}_{2}$ concentration, typically $1 \%$ increase per year compounded (for the actual rates see Table 1). Due to the large inertia of the ocean, the coupled models react slowly to the increase of $\mathrm{CO}_{2}$ and never reach an equilibrium with the forcing. These model runs need a considerable amount of computing resources, so currently only a few groups have performed this type of experiment. For this particular investigation, 5 models were selected whose performance has already been documented and intercompared (IPCC 1992, Gates et al. 1993, Cubasch et al. 1995a; cf. Table 1). The results of these models were collected at the Deutsches Klimarechenzentrum (DKRZ; German Climate Computing Centre) on behalf of the IPCC, and were interpolated to a common grid (Fig. 1a; T21 $=5.6^{\circ}$ ). Since all models use different $\mathrm{CO}_{2}$ forcings and since they all have a different climate sensitivity, the data used were averages over the 10 years around the time of $\mathrm{CO}_{2}$ doubling Throughout this study we only consider the land 
Table 1. Transient $\mathrm{CO}_{2}$ experiments with 5 different OAGCMs. LSG: large-scale geostrophic ocean model; OPYC: isopycral ocean model

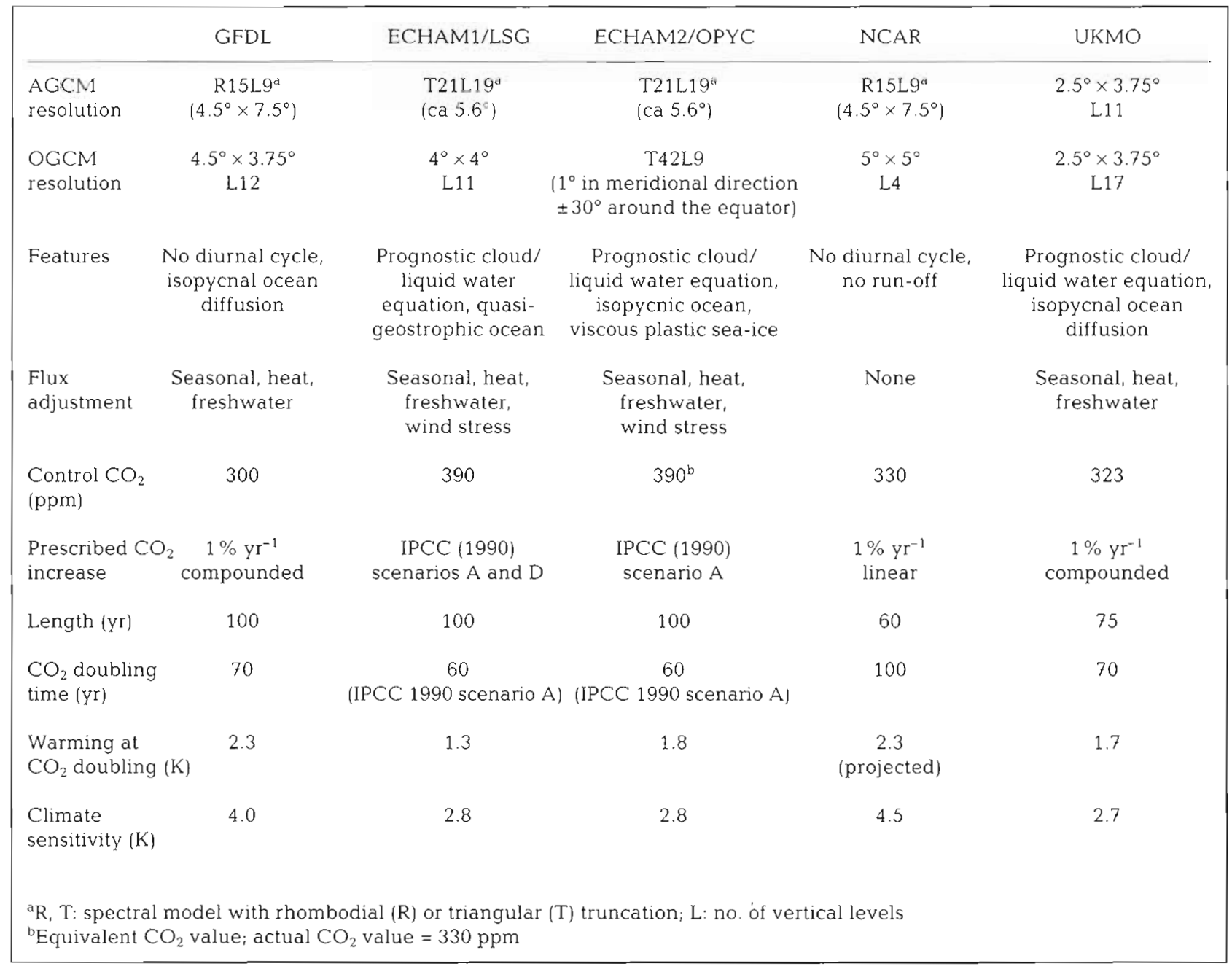

points. Table 2 gives the coordinates of the region analysed which coincides with the 'Southern Europe' region suggested by IPCC (1990). Fig. 1 shows the distribution of the land and sea points for the 3 resolutions considered.

The other regions proposed by IPCC (1990) have been analysed in Cubasch et al. (1995b). The correlation was calculated after subtraction of the mean.

Table 2. Region selected for this study. See IPCC (1990) for discussion

\begin{tabular}{|ccc|}
\hline Boundaries & Location & $\begin{array}{c}\text { No. of land- } \\
\text { points in area }\end{array}$ \\
\hline- & Southern & T21 (ca 5.6 $\left.6^{\circ}\right): 31$ \\
$10^{\circ} \mathrm{W}-45^{\circ} \mathrm{E}$ & Europe & T42 (ca 2.8 $): 76$ \\
$35^{\circ}-50^{\circ} \mathrm{N}$ & T106 (ca 1.1 $\left.1^{\circ}\right): 439$ \\
& & \\
\hline
\end{tabular}

The model data were compared with the rainfall and the surface temperature data as in Legates \& Willmott (1990) and a number of local precipitation time series (Section 4). The data for the observed DTR were provided by May et al. (1992).

\section{DIRECTIY INTERPOLATED REGIONAL RESULTS}

\subsection{Near-surface temperature and its change}

In winter, all 5 experiments mentioned above display a realistic temperature maximum over the central Mediterranean Sea (Fig. 2). However, at the northeastern border of the area the UKMO simulation is too cold, thus generating an unrealistically high temperature gradient. The objective analysis shows that the climate pattern is quite similarly predicted during winter by all the models with correlations in excess of $87 \%$ 
Table 3. Surface temperature in winter (DJF) for the 5 OAGCMs and the observations. Upper triangle: correlation; lower triangle: RMS

\begin{tabular}{|c|c|c|c|c|c|c|}
\hline & GFDL & $\begin{array}{c}\text { ECHAM1 } \\
\text { /LSG }\end{array}$ & $\begin{array}{c}\text { ECHAM2 } \\
\text { /OPYC }\end{array}$ & NCAR & UKMO & Observ. \\
\hline GFDL & & $84 \%$ & $85 \%$ & $91 \%$ & $86 \%$ & $87 \%$ \\
\hline ECHAM1/LSG & $3.3 \mathrm{~K}$ & & $96 \%$ & $85 \%$ & $84 \%$ & $88 \%$ \\
\hline ECHAM2/OPYC & $3.3 \mathrm{~K}$ & $1.6 \mathrm{~K}$ & & $88 \%$ & $90 \%$ & $96 \%$ \\
\hline NCAR & $2.9 \mathrm{~K}$ & $3.8 \mathrm{~K}$ & $3.4 \mathrm{~K}$ & & $90 \%$ & $91 \%$ \\
\hline UKMO & $5.6 \mathrm{~K}$ & $6.3 \mathrm{~K}$ & $5.4 \mathrm{~K}$ & $5.1 \mathrm{~K}$ & & $94 \%$ \\
\hline Observations & $3.3 \mathrm{~K}$ & $3.0 \mathrm{~K}$ & $2.4 \mathrm{~K}$ & $3.0 \mathrm{~K}$ & $5.7 \mathrm{~K}$ & \\
\hline
\end{tabular}

Table 4. Change of surface temperature in winter (DJF) for the 5 OAGCMs. Upper triangle: correlation; lower triangle: RMS

\begin{tabular}{|lcccrc|}
\hline & GFDL & $\begin{array}{c}\text { ECHAM1 } \\
\text { /LSG }\end{array}$ & $\begin{array}{c}\text { ECHAM2 } \\
\text { /OPYC }\end{array}$ & NCAR & UKMO \\
\hline GFDL & & $13 \%$ & $2 \%$ & $43 \%$ & $87 \%$ \\
ECHAM1/LSG & $1.1 \mathrm{~K}$ & - & $62 \%$ & $-49 \%$ & $-8 \%$ \\
ECHAM2/OPYC & $0.9 \mathrm{~K}$ & $0.6 \mathrm{~K}$ & & $15 \%$ & $22 \%$ \\
NCAR & $0.9 \mathrm{~K}$ & $0.7 \mathrm{~K}$ & $0.4 \mathrm{~K}$ & & $58 \%$ \\
UKMO & $1.3 \mathrm{~K}$ & $2.1 \mathrm{~K}$ & $1.9 \mathrm{~K}$ & $1.8 \mathrm{~K}$ & \\
\hline
\end{tabular}

Table 5. Surface temperature in summer (JJA) for the 5 OAGCMs and the observations. Upper triangle: correlation; lower triangle: RMS

\begin{tabular}{|lcrrrrr|} 
& GFDL & $\begin{array}{c}\text { ECHAM1 } \\
\text { /LSG }\end{array}$ & $\begin{array}{c}\text { ECHAM2 } \\
\text { /OPYC }\end{array}$ & NCAR & UKMO & Observ. \\
\hline GFDL & & $62 \%$ & $64 \%$ & $69 \%$ & $77 \%$ & $84 \%$ \\
ECHAM1/LSG & $3.3 \mathrm{~K}$ & & $87 \%$ & $9 \%$ & $80 \%$ & $72 \%$ \\
ECHAM2/OPYC & $4.9 \mathrm{~K}$ & $3.5 \mathrm{~K}$ & & $2 \%$ & $82 \%$ & $84 \%$ \\
NCAR & $4.6 \mathrm{~K}$ & $6.8 \mathrm{~K}$ & $9.1 \mathrm{~K}$ & & $22 \%$ & $30 \%$ \\
UKMO & $5.5 \mathrm{~K}$ & $4.8 \mathrm{~K}$ & $3.1 \mathrm{~K}$ & $9.5 \mathrm{~K}$ & & $93 \%$ \\
Observations & $4.8 \mathrm{~K}$ & $4.3 \mathrm{~K}$ & $2.5 \mathrm{~K}$ & $8.7 \mathrm{~K}$ & $2.3 \mathrm{~K}$ & \\
\hline
\end{tabular}

northeast/southwest gradient. The ECHAM1/LSG simulation has a local minimum of warming in the central Mediterranean region (Fig. 3).

The temperature change pattern is only well correlated in the UKMOGFDL combination, while the 2 ECHAM simulations are even anticorrelated (Table 4). This shows that even though the simulation of the present day climate in both models is quite similar, their response depends strongly on the parameterization and on the ocean model used. The intermodel RMS values, however, are smaller than the model error, which indicates that even though the patterns of climate change are quite different, the amplitudes are quite similar.

The correlation between the simulations and the observations is generally lower in summer than in winter (Table 5). The NCAR results are only marginally correlated to the observations and the other models. One has to bear in mind that the mean has been subtracted. The climate drift of this model should have, therefore, no direct impact on the correlation. The climate drift of the NCAR model can clearly be seen in the RMS, which exceeds $8 \mathrm{~K}$ where the model is compared to the observations. Contrary to winter, in summer the UKMO center model has the smallest error, thus confirming the visual impression.

In summer, the NCAR model simulates a ridge with extremely high temand in 1 case (ECHAM2/OPYC) higher than 95\% (Table 3). The models correlate to each other at a slightly lesser degree than to the observations (between 84 and 96\%). The statement that the model simulations are much closer to each other than to the observations does not hold for the surface temperature field. The RMS error lies between $2.4 \mathrm{~K}$ (ECHAM2/ OPYC) and $5.7 \mathrm{~K}$ (UKMO). The inter-model RMS difference is smallest for the 2 ECHAM simulations, while the UKMO simulation differs most from all other models and the observations.

in the climate change experiments, i.e. at $2 \times \mathrm{CO}_{2}$ (doubled $\mathrm{CO}_{2}$ ) conditions, the UKMO and the GFDL models predict the largest temperature change (compared to their respective control experiments) of all simulations, with the maximum warming at the northeastern edge of the area considered and a strong peratures stretching from the Black Sea to central France (Fig. 2). Only the UKMO and ECHAM2/OPYC simulations realistically reproduce the slight northwest/southeast temperature gradient. There is a tendency in all simulations to overemphasize the temper-

The climate change in summer is quite differently simulated by the models (Fig. 3). In the NCAR simulation, it barely exceeds $1.5 \mathrm{~K}$, with a minimum extending from the Pyrenees via the north of the Alps to the Balkans and Crete, while the GFDL simulation has a maximum in the same region with values exceeding $5 \mathrm{~K}$. The UKMO simulation predicts the greatest warming in the northeast and southwest.

The objective scores confirm that the pattern of change is quite different between the models in summer as well (Table 6). The highest correlation value ature over the southern Iberian Peninsula. 
is $74 \%$ (NCAR-ECHAM2/OPYC). In every third experiment the correlation coefficient is negative. The RMS differences are slightly higher than in winter and lower than the error when compared to the observations.

In winter the model-simulated patterns compare quite well with the observations and among themselves. In summer, the correlation is weaker and the RMS error and inter-model deviation are larger. In this season, the NCAR model has the worst performance and can barely be compared to the other models. For $2 \times \mathrm{CO}_{2}$ conditions in winter and summer, the models simulate climate change with comparable amplitudes, but with quite different patterns, which can even be anticorrelated

\subsection{Precipitation and its change}

In winter, all models roughly simulate the observed pattern of precipitation. Its maximum stretches from the Bay of Biscay via central Italy to the Balkans and the African continent (Fig. 4). The amplitude, however, is different in the various models and shows the largest deviations over North Africa.

The objective verification gives the highest correlation between model and observations for the UKMO simulation, while the ECHAM2/OPYC experiment, which performed best for temperature, has almost no correlation to the observations (Table 7). The models correlate better to each other than to the observations. The RMS error is smallest in the GFDL simulation and largest in both the ECHAM experiments. The inter-model differences are as large as the differences to the observations.

In all simulations but one (ECHAM2/OPYC), the central and northern parts of Southern Europe become wetter, while a narrow band at the southern edge of the region becomes dryer (Fig. 5). The fact that the pattern of precipitation change is not very consistent between the models is reflected in the objective comparison (Table 8). The precipitation change patterns only correlate in 2 cases (of 10 possible combinations) at more than $50 \%$. The RMS differences between the models have a maximum of $0.4 \mathrm{~mm} \mathrm{~d}^{-1}$. Therefore, the similarity of the change patterns is as large as the similarity between the observed and simulated patterns.
Upe of surface temperature in summer (JJA) for the
Upperiangle: correlation; lower triangle: RMS

\begin{tabular}{ccccc} 
GFDL & $\begin{array}{c}\text { ECHAM1 } \\
\text { /LSG }\end{array}$ & $\begin{array}{c}\text { ECHAM2 } \\
\text { /OPYC }\end{array}$ & NCAR & UKMO \\
& $8 \%$ & $-42 \%$ & $-50 \%$ & $38 \%$ \\
$2.6 \mathrm{~K}$ & & $13 \%$ & $-17 \%$ & $29 \%$ \\
$2.8 \mathrm{~K}$ & $1.0 \mathrm{~K}$ & & $74 \%$ & $31 \%$ \\
$3.5 \mathrm{~K}$ & $1.2 \mathrm{~K}$ & $1.2 \mathrm{~K}$ & & $10 \%$ \\
$1.5 \mathrm{~K}$ & $1.6 \mathrm{~K}$ & $1.6 \mathrm{~K}$ & $2.4 \mathrm{~K}$ & \\
\hline
\end{tabular}

Upper triangle: correlation; lower triangle: RMS $\left(\mathrm{mm} \mathrm{d}^{-1}\right)$

\begin{tabular}{|lcccccc|}
\hline & GFDL & $\begin{array}{c}\text { ECHAM1 } \\
\text { /LSG }\end{array}$ & $\begin{array}{c}\text { ECHAM2 } \\
\text { /OPYC }\end{array}$ & NCAR & UKMO & Observ. \\
\hline GFDL & & $35 \%$ & $27 \%$ & $53 \%$ & $45 \%$ & $53 \%$ \\
ECHAM1/LSG & 1.0 & & $62 \%$ & $76 \%$ & $63 \%$ & $26 \%$ \\
ECHAM2/OPYC & 1.0 & 0.9 & & $49 \%$ & $43 \%$ & $13 \%$ \\
NCAR & 0.9 & 1.2 & 1.4 & & $57 \%$ & $44 \%$ \\
UKMO & 0.9 & 1.0 & 1.2 & 0.9 & & $56 \%$ \\
Observations & 0.6 & 1.2 & 1.2 & 0.9 & 0.8 & \\
\hline
\end{tabular}

Table 8. Change of precipitation in winter (DJF) for the 5 OAGCMs. Upper triangle: correlation; lower triangle: RMS ( $\mathrm{mm} \mathrm{d}^{-1}$ )

\begin{tabular}{|lccccc|}
\hline & GFDL & $\begin{array}{c}\text { ECHAM1 } \\
\text { /LSG }\end{array}$ & $\begin{array}{c}\text { ECHAM2 } \\
\text { /OPYC }\end{array}$ & NCAR & UKMO \\
\hline GFDL & & $41 \%$ & $6 \%$ & $48 \%$ & $48 \%$ \\
ECHAM1/LSG & 0.3 & & $45 \%$ & $38 \%$ & $51 \%$ \\
ECHAM2/OPYC & 0.3 & 0.2 & & $13 \%$ & $23 \%$ \\
NCAR & 0.2 & 0.4 & 0.4 & & $64 \%$ \\
UKMO & 0.3 & 0.3 & 0.4 & 0.3 & \\
\hline
\end{tabular}

In summer, the structures of precipitation simulated by the models show a better agreement than in winter. They all, with the exception of the NCAR model, simulate the observed gradient of high rainfall in the north and low precipitation in the south of the region analysed. The mean level, however, is different among the models and only the UKMO and GFDL simulations compare favorably with the observations (Fig. 4). This visual result is corroborated by the objective analysis (Table 9). All the models, with the exception of the NCAR model, correlate well (and much better than in winter) with the observations and among themselves i.e. the patterns are similar. The RMS error is smallest for the GFDL and UKMO simulations. The models are about as good in simulating each other as in simulating the observations

The change of precipitation in summer at the time of $\mathrm{CO}_{2}$ doubling is rather inconsistent (Fig. 5). The largest decrease is simulated in the UKMO model (it was among the wettest), followed by the GFDL model, 

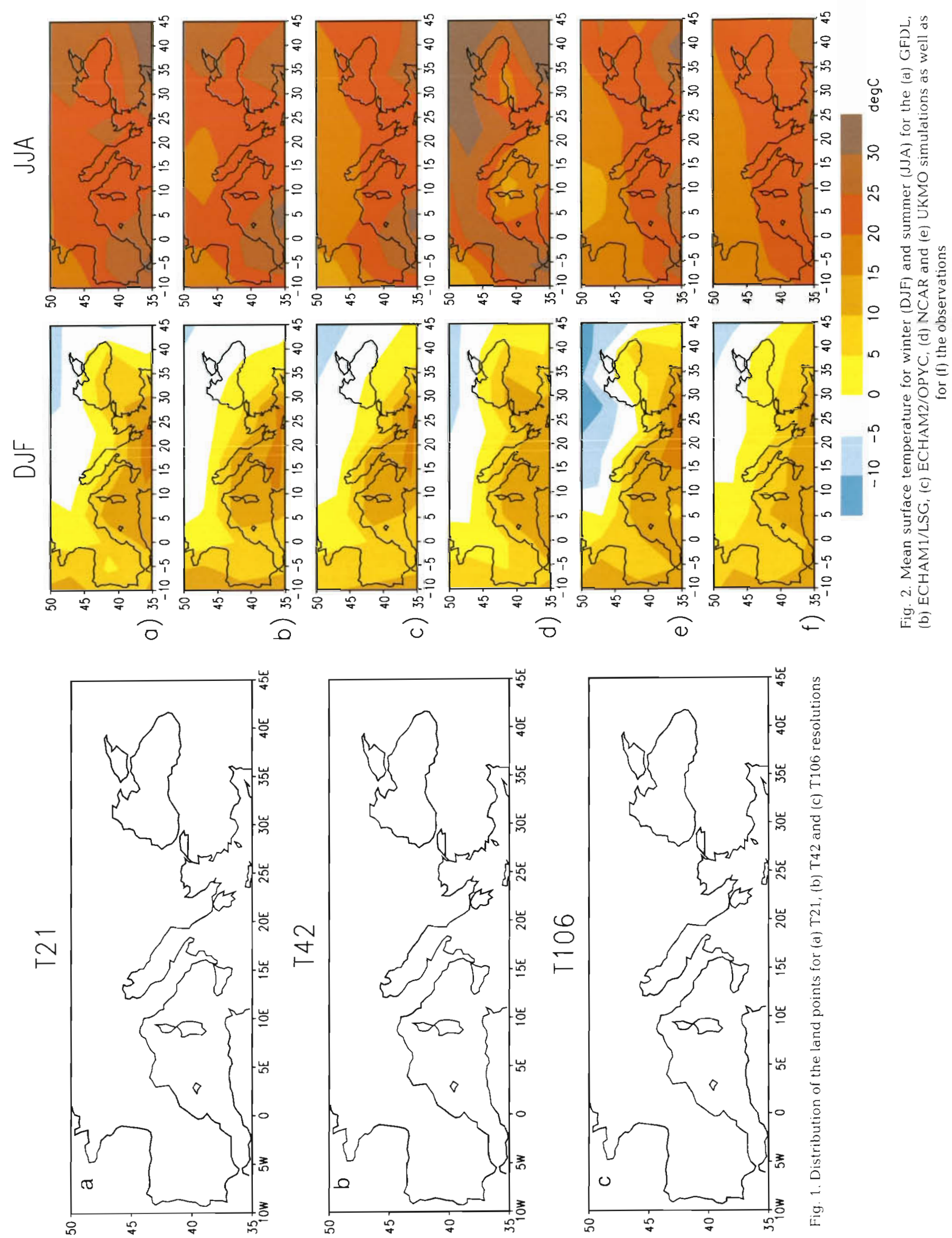

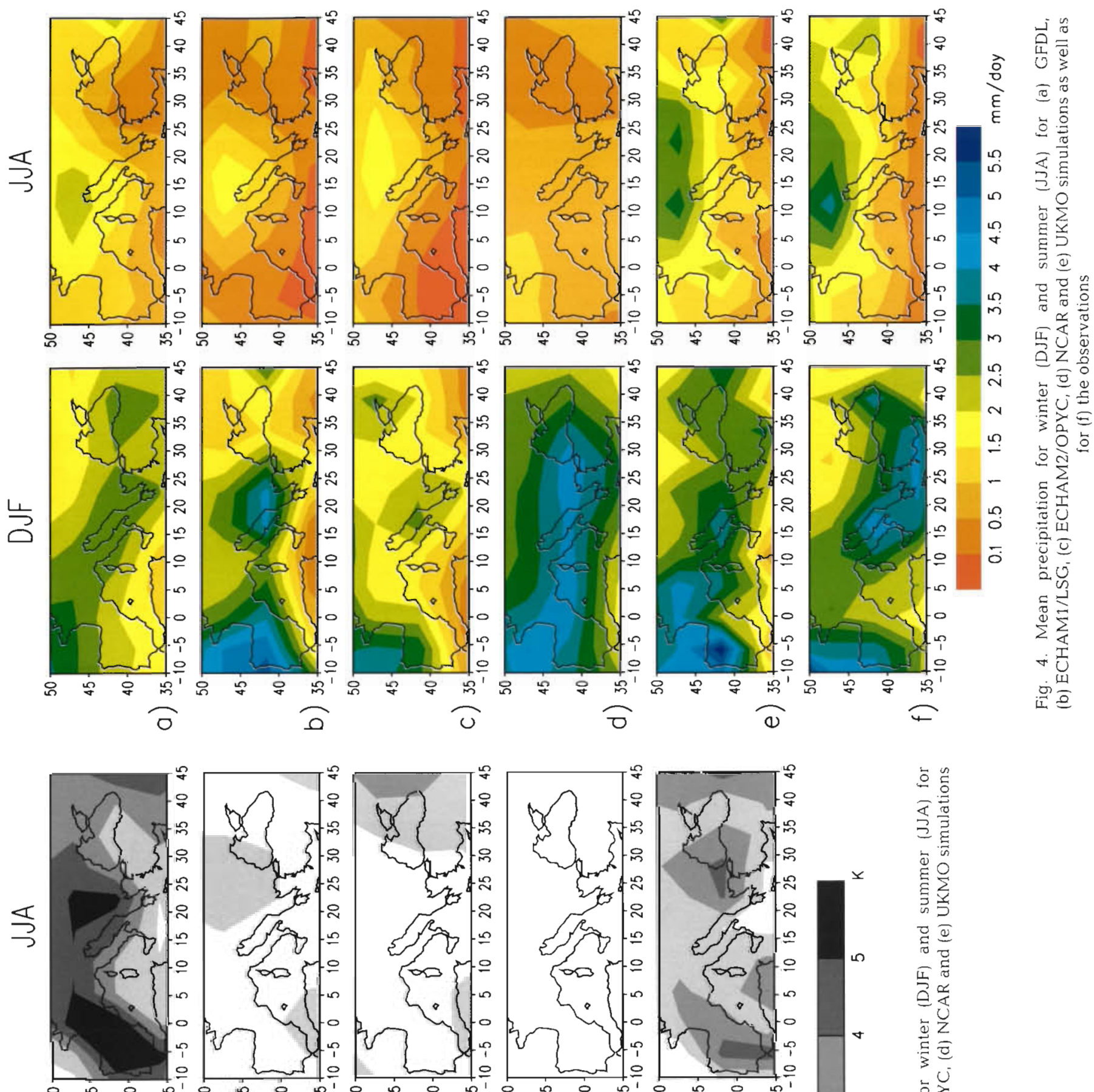

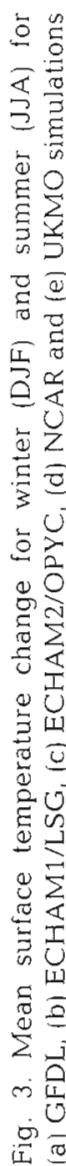
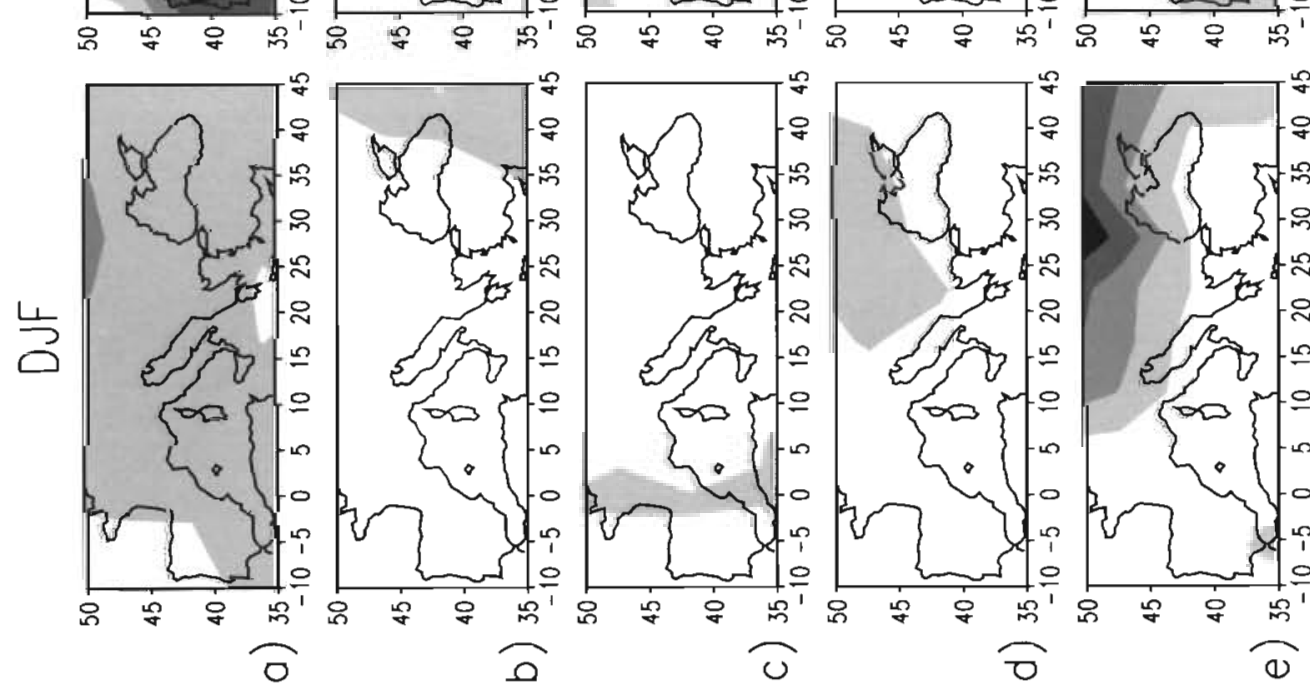

穴沓

포

음

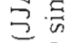

氙

क

च

巫交

중응

更

곤

要

0

迹

$\dot{T} U$

호을 
Table 9. Precipitation in summer (JJA) for the 5 OAGCMs and the observations Upper triangle: correlation; lower triangle: RMS ( $\mathrm{mm} \mathrm{d}^{-1}$ )

\begin{tabular}{|lcccccc|}
\hline & GFDL & $\begin{array}{c}\text { ECHAM1 } \\
\text { /LSG }\end{array}$ & $\begin{array}{c}\text { ECHAM2 } \\
\text { /OPYC }\end{array}$ & NCAR & UKMO & Observ. \\
\hline GFDL & & $64 \%$ & $60 \%$ & $25 \%$ & $81 \%$ & $86 \%$ \\
ECHAM1/LSG & 0.9 & & $77 \%$ & $5 \%$ & $66 \%$ & $72 \%$ \\
ECHAM2/OPYC & 0.7 & 0.4 & & $-2 \%$ & $69 \%$ & $81 \%$ \\
NCAR & 0.8 & 0.5 & 0.6 & & $4 \%$ & $6 \%$ \\
UKMO & 0.8 & 1.5 & 1.3 & 1.4 & & $88 \%$ \\
Observations & 0.8 & 1.5 & 1.3 & 1.5 & 0.5 & \\
\hline
\end{tabular}

Table 10. Change of precipitation in summer (JJA) for the 5 OAGCMs. Upper triangle: correlation; lower triangle: RMS ( $\left.\mathrm{mm} \mathrm{d}^{-1}\right)$

\begin{tabular}{|lcccrr|} 
& GFDL & $\begin{array}{c}\text { ECHAM1 } \\
\text { /LSG }\end{array}$ & $\begin{array}{c}\text { ECHAM2 } \\
\text { /OPYC }\end{array}$ & NCAR & UKMO \\
\hline GFDL & & $27 \%$ & $-11 \%$ & $1 \%$ & $60 \%$ \\
ECHAM1/LSG & 0.2 & & $-25 \%$ & $-54 \%$ & $3 \%$ \\
ECHAM2/OPYC & 0.5 & 0.4 & & $53 \%$ & $-5 \%$ \\
NCAR & 0.4 & 0.3 & 0.2 & & $-24 \%$ \\
UKMO & 0.2 & 0.4 & 0.5 & 0.5 & \\
\hline
\end{tabular}

coherent climate change pattern. We cannot assess at present what causes these differences. They might be generated by the different model formulations, but possibly also by the different experimental procedures. A 'coupled model intercomparison project' (CMIP) has recently been launched by the 'climate variability and predictability programme' (CLIVAR) to study the coupled model behaviour in the control climate and to conduct transient experiments under controlled conditions.

\section{TIME-SLICE EXPERIMENTS}

One obvious solution for increasing confidence in the models is an increase in the resolution, since, at least in weather forecasting, it has been proven that performance can be improved by increasing the resolution.

whereas an increase was found with the NCAR and ECHAM2/OPYC models. This is reflected in the pattern correlation coefficients (Table 10), which were as high as 60\% (UKMO-GFDL) and as low as $-54 \%$ (ECHAM1/LSG-NCAR). The RMS difference between the model-simulated change is as high in summer as in winter, but smaller than the model error.

Generally, the simulation of the precipitation field is less accurate than that of the temperature field; but, in contrast to temperature, it is better in summer (with the exception of the NCAR model, the simulation of which is basically uncorrelated with the observations in summer). The models are as good (or bad) in predicting the observations as they are in predicting each other The simulated climate change of the models is only marginally consistent, with correlations not exceeding $64 \%$.

\subsection{Discussion}

The models seem to be capable of simulating the present day climate with similar degrees of accuracy. However, a good performance in predicting the surface temperature does not imply a good simulation of the precipitation and vice versa. The spectrum of results under $2 \times \mathrm{CO}_{2}$ conditions strongly indicates that the models in their currently used forms are not capable of predicting climate change in a consistent manner. This study gives a picture of the range of possible realizations obtained by the models rather than a
With the coarse resolution of $\mathrm{T} 21$, or equivalents, the regional details cannot adequately be resolved (cf. Fig. 1a). The limiting factor to increasing the resolution is the computing time which is increased by the third power of the resolution, i.e. a doubling of resolution demands an 8-fold increase in computing time. Additionally, with the transient experiments one obtains only 1 single realization. The statistical stability of the result is therefore poor. One solution for overcoming these problems is the application of the time-slice method (Cubasch et al. 1995b).

\subsection{Models}

In the time-slice method, an atmosphere model is forced by the greenhouse gas concentration corresponding to a certain time in the future, e.g. in this case at the time of $\mathrm{CO}_{2}$ doubling, while the sea-surface temperature (SST) and sea ice distribution are taken from the transient coarse-grid simulation (ECHAM1/LSG, Cubasch et al. 1992) mentioned above (cf. Table 1). This method has the advantage that the model can be integrated with a high resolution over several decades around the time of interest, so it gives a large statistical sample of the changed climate, similarly to equilibrium experiments with mixed-layer models (IPCC 1990). Additionally, it has a more credible distribution of SST than the mixed layer models. To what extent the SST climate change patterns from the UKMO and ECHAM1/LSG simulations influence the results has 
been addressed by Mahfouf et al. (1994). An assessment of the performance of the T21 ECHAM3 model in time-slice experiments in the various IPCC regions has been documented in Cubasch et al. (1995a).

The models employed in the present study are the T21, T42 and T106 versions of the ECHAM3 model (DKRZ 1993). They use a spectral transform model with a triangular truncation and have a vertical resolution of 19 levels. A detailed description of the models and a documentation of their performance have been presented by Roeckner et al. (1992), Arpe et al. (1994), Bengtsson et al. (1994a) and Gleckler et al. (1994). The T21 and T42 models have been integrated for $30 \mathrm{yr}$, while the T106 model has only been run for $5 \mathrm{yr}$.

The objective verification of the various horizontal resolutions was done by interpolating the data to a common high-resolution grid. In the present analysis, the $0.5^{\circ}$-resolution temperature and precipitation grid of the observed data was used. The data for the DTR were interpolated from their original $2.5 \times 2.5^{\circ} \mathrm{grid}$ to the $0.5^{\circ}$ mesh

\subsection{Temperature and its change}

The observed winter temperatures show the influence of the maritime regions (Fig. 6). While the highest temperatures follow the coastlines closely, the lowest temperatures are observed in the continental regions of eastern Europe. All model versions simulate the general southwest-northeast temperature gradient, however, only the T106 model is capable of simulating the structure of the temperatures following the coastlines. It appears that even T106 resolution is not quite sufficient to simulate all the details found in the observations.

The fact that the general temperature pattern is simulated with a similar quality in all resolutions is reflected in the the correlation coefficient, which is almost independent of the resolution used. Only the RMS shows a tendency to improve with increased resolution (Table 11). The T42 model is generally more similar to the T106 model than to the T21 model; the deviation of the T21 model from the T106 model is larger than the difference of all models to the observations.

The change of the temperature is quite differently simulated by the different model versions. In the T106 model the temperature change rises progressively from the west to the east with maxima exceeding $5 \mathrm{~K}$ east of the Black Sea. The T21 and the T42 models, however, simulate a north-south temperature rise gradient with a minimum over the central Mediterranean Sea. The pattern simulated by the T42 model resembles the T21 model more than the T106 model. This is reflected in the inter-model pattern correlation, which is only high for the T42 and T21 model (Table 12). The model differences (RMS) are generally smaller than the model errors.

The results for summer confirm those found for winter. The low resolution models are not capable of simulating all the detailed structures found in the highresolution model or the observations, which leads, particularly in water-enclosed land regions like Italy or the Iberian Pensinsula, to considerable temperature errors. The anomaly correlation indicates a significant improvement with increased resolution when going from T21 to both higher resolutions, while the improvement from T42 to T106 is only marginal. The RMS error is almost resolution independent (Table 13).

The simulated temperature change, as in winter, increases with resolution. The low-resolution models have relatively more coastal points (i.e. land points which have at least 1 sea point as neighbour) and therefore a more maritime climate character than the high-resolution model. The ratio of continental points (i.e. land points which are surrounded by adjoining land points) to total land points for the 3 resolutions is: T21, 11/31; T42, 18/76; T106, 270/439. These maritime points dampen the response due to the inertia of the

Table 11. Near surface temperature in winter (DJF) for the 3 resolutions and the obscrvations. Upper triangle: correlation; lower triangle: RMS

\begin{tabular}{|lcccc|}
\hline & T21 & T42 & T106 & Observations \\
\hline T21 & & $91 \%$ & $77 \%$ & $87 \%$ \\
T42 & $2.4 \mathrm{~K}$ & & $91 \%$ & $86 \%$ \\
T106 & $3.6 \mathrm{~K}$ & $2.1 \mathrm{~K}$ & & $86 \%$ \\
Observ. & $2.9 \mathrm{~K}$ & $2.6 \mathrm{~K}$ & $2.5 \mathrm{~K}$ & \\
\hline
\end{tabular}

Table 12. Near surface temperature change in winter (DJF) for the 3 resolutions. Upper triangle: correlation; lower triangle: RMS

\begin{tabular}{|lccc|}
\hline & T21 & T42 & T106 \\
\hline T21 & & $75 \%$ & $44 \%$ \\
T42 & $0.4 \mathrm{~K}$ & & $55 \%$ \\
T106 & $1.2 \mathrm{~K}$ & $1.0 \mathrm{~K}$ & \\
\hline
\end{tabular}

Table 13. Near surface temperature in summer (JJA) for the 3 resolutions and the observations. Upper triangle: correlation; lower triangle: RMS

\begin{tabular}{|lcccc|}
\hline & T21 & T42 & T106 & Observations \\
\hline T21 & & $81 \%$ & $60 \%$ & $70 \%$ \\
T42 & $3.4 \mathrm{~K}$ & & $86 \%$ & $85 \%$ \\
T106 & $4.2 \mathrm{~K}$ & $2.0 \mathrm{~K}$ & & $86 \%$ \\
Observ. & $2.9 \mathrm{~K}$ & $2.8 \mathrm{~K}$ & $2.8 \mathrm{~K}$ & \\
\hline
\end{tabular}



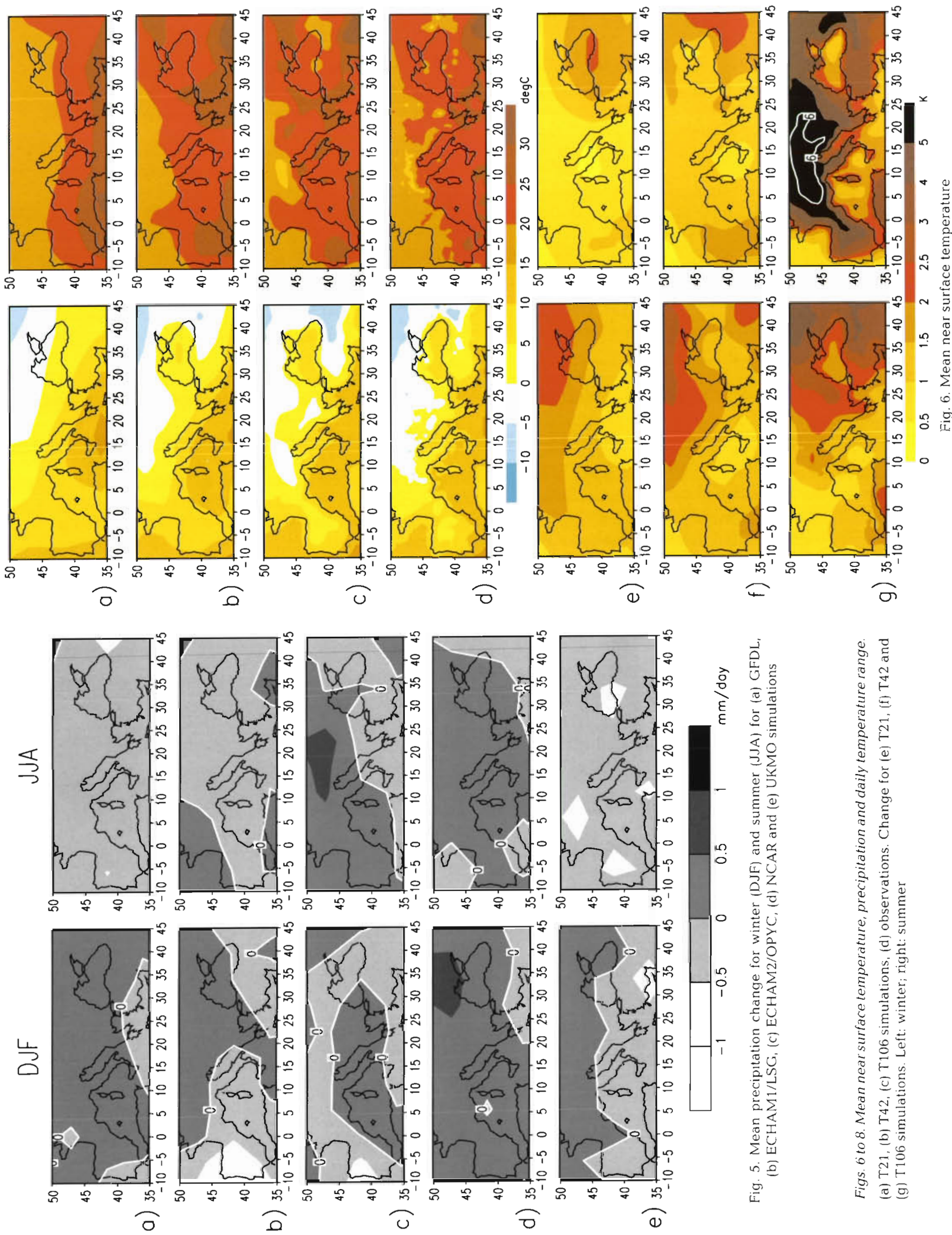

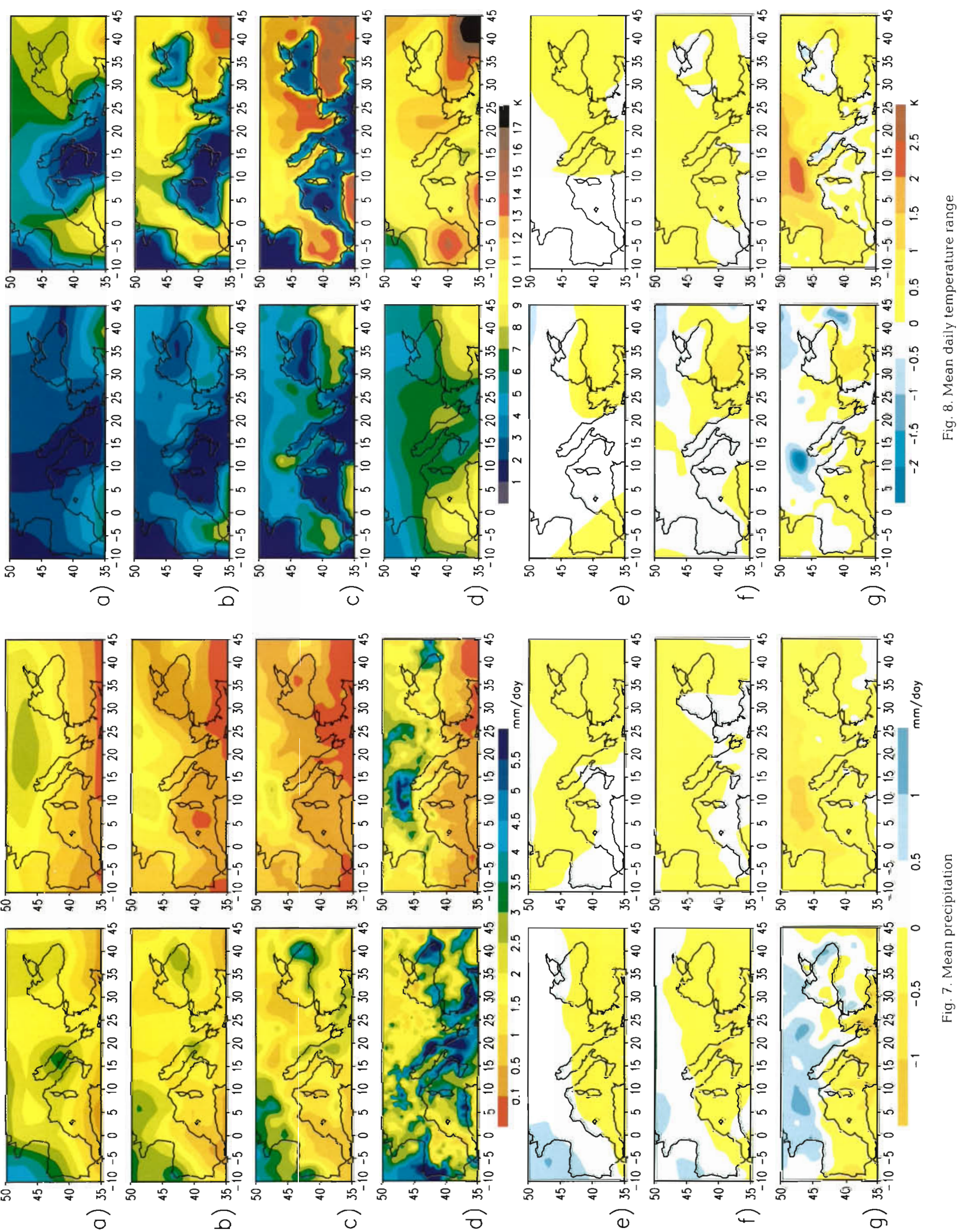
Table 14. Near surface temperature change in summer (JJA) for the 3 resolutions. Upper triangle: correlation; lower triangle: RMS

\begin{tabular}{|lccc|}
\hline & T21 & T42 & T106 \\
\hline T21 & & $73 \%$ & $-43 \%$ \\
T42 & $0.5 \mathrm{~K}$ & & $-20 \%$ \\
T106 & $3.5 \mathrm{~K}$ & $3.4 \mathrm{~K}$ & \\
\hline
\end{tabular}

adjacent sea and because they tend to have higher soil moisture. The T106 model has the largest temperature rises with values exceeding $6 \mathrm{~K}$ directly over the continental land regions. The T21 and T42 models simulate a temperature increase up to $3 \mathrm{~K}$ with a maximum over land at the eastern edge of the area considered. The objective comparison shows only a small correlation in the climate change pattern. Between T106 and the simulations with the lower resolution it is even nogative (Table 14). The RMS inter-model difference is larger than the model error for the T106 model relative to the others.

Generally, for the simulation of the present day climate, the T42 model shows a closer resemblance to the T106 model than to the T21 model. The quality of the simulation increases with resolution. It has been estimated in a statistical study by Waszkewitz (1996) that the additional expense in computing time is worth the gain in simulation quality. For the simulated climate change, the T42 model produces a pattern more similar to the T21 model. Both models have a comparably high share of grid points adjacent to the sea. Therefore their response to a climate change can be described as maritime, i.e. with only a small amplitude and only a weak seasonal signal. The T106 model, on the other hand, has more continental land points. Its response is therefore much stronger and shows a well-defined seasonal variation.

\subsection{Precipitation and its change}

The observed winter precipitation shows distinct maxima at the west side of the coasts (Fig. 7). It has a lot of small-scale structure, which is not even resolved at the highest model resolution. While the east-west precipitation gradient over Spain is visible in all model resolutions, the precipitation structures of Italy, Greece and Asia Minor are only poorly simulated.

The correlation between the observation and the model simulation is small (below $36 \%$ ), but it increases significantly with increased resolution. The RMS error apears to be resolution-independent (Table 15)

The precipitation change pattern has the same basic structure at all 3 resolutions, with an increase in the northern and western parts of the region, and a decrease in the southern and eastern parts. This gradient is smooth in the T21 simulation, is structured in the T106 simulation.

The smooth pattern of the T21 simulation compares well with the T42 pattern, but otherwise the models do not predict each other's climate change well (Table 16). The inter-model differences (RMS) are as large as the differences between the models in the control simulation (Table 15).

The dominant features in the summer observations are a rainfall maximum in the Alps and a distinct north-south gradient with the largest amount of precipitation in the north. This north-south gradient is simulated in all resolutions, but only the highest resolution reproduces the observed rainfall maximum which follows the Mediterranean coastline. There are hints of the rainfall maximum over the Alps in the T106 simulation, but its amplitude is underestimated by a factor of 2 . Other observed rainfall maxima, like the one on the east coast of the Black Sea, cannot be found in any simulation.

The correlation of the patterns is better in summer than in winter (Table 17) with the lowest resolution giving the lowest coefficient. For the T21 resolution,

Table 15. Precipitation in winter (DJF) for the 3 resolutions and the observations. Upper triangle: correlation; lower triangle: RMS $\left(\mathrm{mm} \mathrm{d}^{-1}\right)$

\begin{tabular}{|lcccc|}
\hline & T21 & T42 & T106 & Observations \\
\hline T21 & & $69 \%$ & $47 \%$ & $19 \%$ \\
T42 & 0.5 & & $76 \%$ & $23 \%$ \\
T106 & 0.7 & 0.5 & & $35 \%$ \\
Observ. & 1.6 & 1.7 & 1.6 & \\
\hline
\end{tabular}

Table 16. Precipitation change in winter (DJF) for the 3 resolutions. Upper triangle: correlation; lower triangle: RMS $\left(\mathrm{mm} \mathrm{d}^{-1}\right)$

\begin{tabular}{|lccc|}
\hline & T21 & T42 & T106 \\
\hline T21 & & $85 \%$ & $46 \%$ \\
T42 & 0.2 & & $38 \%$ \\
T106 & 0.4 & 0.5 & \\
\hline
\end{tabular}

Table 17 Precipitation in summer (JJA) for the 3 resolutions and the observations. Upper triangle: correlation; lower triangle: RMS ( $\mathrm{mm} \mathrm{d}^{-1}$ )

\begin{tabular}{|lcccc|}
\hline & T21 & T42 & T106 & Observations \\
\hline T21 & & $74 \%$ & $59 \%$ & $77 \%$ \\
T42 & 0.8 & & $90 \%$ & $82 \%$ \\
T106 & 1.1 & 0.4 & & $82 \%$ \\
Observ. & 0.8 & 1.2 & 1.4 & \\
\hline
\end{tabular}


the RMS error is lower than for the other models because its mean value is higher than in winter. As will be described in Section 4.5, the annual cycle is incorrectly simulated in the $\mathrm{T} 21$ model, giving the highest precipitation in summer. All the models have a mean bias of being too low, which is compensated for in this particular season by the erroneous seasonal cycle of the T21 model. The T21 model therefore shows the lowest RMS error for the wrong reason.

ln the summer season, the higher resolutions generally predict a drier climate under $2 \times \mathrm{CO}_{2}$ conditions. The highest resolution simulates a particularly strong decrease in the rainfall over and north of the Alps (here it has a rainfall maximum). Only the T21 model predicts an increase of the rainfall over Spain. The objective comparison shows agreement in the patterns simulated by the T106 and T42 models, while the T21 model is even anticorrelated with the T42 and T106 simulations (Table 18). The inter-model differences are smaller than the observational error.

In summary, an increase in resolution improves the simulation of the precipitation pattern, but not the amplitude. The precipitation is simulated better for the summer than the winter.

Generally, the precipitation is governed by the large-scale flow and the local moisture supply. Apparently, the size of the moisture convergence and/or its conversion to precipitation is underestimated. The fact that the precipitation pattern simulation is correlated to the observation more in summer than in winter points to problems with the moisture convergence connected to the large-scale flow. This is consistent with the results of Machenhauer et al. (1996), which show that due to systematic model deficiencies the flow simulated by the T42 model in winter comes from a too southerly direction, while in summer the errors in the flow field are small.

The precipitation change is simulated by all model resolutions with a consistent pattern. In summer, no clear climate change signal can be identified going from one resolution to another. Here 2 effects cancel each other out. The T4 2 model has a similar flow to that

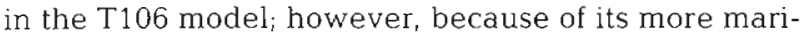
time character, its response to a climate change is rather muted.

Table 18. Precipitation change in summer (JJA) for the 3 resolutions. Upper triangle: correlation; lower triangle: RMS $\left(\mathrm{mm} \mathrm{d}^{-1}\right)$

\begin{tabular}{|cccc|}
\hline & $\mathrm{T} 21$ & $\mathrm{~T} 42$ & $\mathrm{~T} 106$ \\
\hline $\mathrm{T} 21$ & & $-7 \%$ & $-23 \%$ \\
$\mathrm{~T} 42$ & $0.2 \mathrm{~mm} \mathrm{~d}^{-1}$ & & $64 \%$ \\
$\mathrm{~T} 106$ & $0.5 \mathrm{~mm} \mathrm{~d}^{-1}$ & $0.3 \mathrm{~mm} \mathrm{~d}^{-1}$ & \\
\hline
\end{tabular}

\subsection{Daily temperature range and its change}

The DTR in winter is quite differently simulated by the models and shows a sensible structure only for the T106 resolution, i.e. the continents show a higher range than the sea regions (Fig. 8). However, the DTR is underestimated even with T106 resolution. The correlation between the simulations and the observations increases significantly with resolution (Table 19). The T42 simulation is more correlated to the T21 simulation than to the T106 simulation. The RMS error decreases with increased resolution, but again the T42 model is more similar to the T21 model than to the T106 model. The low-resolution models are more similar to each other than to the observations.

The change under $2 \times \mathrm{CO}_{2}$ conditions is quite largescale in the T21 and T42 experiments, with basically a small decrease in the northern and central part of the studied region and a marginal increase everywhere else. The T106 experiment simulates a strong decrease in the Alps, and a marked increase in Algeria and Asia Minor. The pattern of DTR change simulated by the models is not well correlated, again with the T42 model closer resembling the T21 model than the T106 model (Table 20). The inter-model RMS for the change is generally lower than the model errors.

In summer, the T106 model simulates a realistic distribution of the DTR but exaggerates the amplitude, while in the lower resolution models the amplitude is underestimated. The objective analysis confirms a closer correlation and a smaller inter-model difference between the T42 model and the T21 model compared to the T106 model (Table 21). The T106 model is less correlated to the observations than the T21 and T42 models, mainly because it simulates too many detailed

Table 19. Daily temperature range (DTR) in winter (DJF) for the 3 resolutions and the observations. Upper triangle: correlation; lower triangle: RMS

\begin{tabular}{|lcccc|}
\hline & T21 & T42 & T106 & Observations \\
\hline T21 & & $85 \%$ & $65 \%$ & $64 \%$ \\
T42 & $1.3 \mathrm{~K}$ & & $77 \%$ & $73 \%$ \\
T106 & $2.8 \mathrm{~K}$ & $1.9 \mathrm{~K}$ & & $80 \%$ \\
Observ. & $4.0 \mathrm{~K}$ & $3.0 \mathrm{~K}$ & $1.6 \mathrm{~K}$ & \\
\hline
\end{tabular}

Table 20. DTR change in winter (DJF). Upper triangle: correlation; lower triangle: RMS

\begin{tabular}{|lccc|}
\hline & $\mathrm{T} 21$ & $\mathrm{~T} 42$ & $\mathrm{~T} 106$ \\
\hline $\mathrm{T} 21$ & & $68 \%$ & $47 \%$ \\
$\mathrm{~T} 42$ & $0.2 \mathrm{~K}$ & & $43 \%$ \\
$\mathrm{~T} 106$ & $0.4 \mathrm{~K}$ & $0.5 \mathrm{~K}$ & \\
\hline
\end{tabular}


Table 21. Daily temperature range in summer (JJA) for the 3 resolutions and observations. Upper triangle: correlation; lower triangle: RMS

\begin{tabular}{|lcccc|}
\hline & T21 & T42 & T106 & Observations \\
\hline T21 & & $74 \%$ & $56 \%$ & $74 \%$ \\
T42 & $3.0 \mathrm{~K}$ & & $68 \%$ & $75 \%$ \\
T106 & $5.4 \mathrm{~K}$ & $3.1 \mathrm{~K}$ & & $67 \%$ \\
Observ. & $5.0 \mathrm{~K}$ & $2.8 \mathrm{~K}$ & $1.8 \mathrm{~K}$ & \\
\hline
\end{tabular}

Table 22. DTR change in summer (JJA) for the 3 resolutions Upper triangle: correlation; lower triangle: RMS

\begin{tabular}{|lccc|}
\hline & T21 & T42 & T106 \\
\hline T21 & & $6 \%$ & $-44 \%$ \\
T42 & $0.2 \mathrm{~K}$ & & $51 \%$ \\
T106 & $0.9 \mathrm{~K}$ & $0.8 \mathrm{~K}$ & \\
\hline
\end{tabular}

structures not present in the observations, but it has the lowest RMS error. The RMS difference between the models is of the same order as the model error.

The change of the DTR is simulated in summer with only a small amplitude by the T21 and T42 models. The T106 simulates a distinct increase with a maximum over the Alps and stretches northwards.

The objective analysis confirms that the climate change simulated by the T42 model is more similar to the T21 model than to the T106 model (Table 22). The inter-model correlation in the summer season is smaller than in winter-the inter-model differences are higher, but still smaller than the model error.

In summary, one can state that the resolution increases the credibility of the simulation of the DTR. At the same time, the simulated DTR changes of the T42 and T21 models are more similar to each other than to the T106 experiment. However, with the exception of the T106 experiment, the DTR change has very little structure and has only a marginal amplitude.

\subsection{Seasonal cycle and its change}

In Southern Europe, the observed seasonal cycle of the near-surface temperature in summer is simulated well by the T21 model, while both the T42 and the T106 simulations have an error of at most $3 \mathrm{~K}$. In winter, this is reversed. Here, the high-resolution models show only a small error $(<1 \mathrm{~K})$ while the T21 model has an error of about $2.5 \mathrm{~K}$. In the transitional seasons, the error is small (Fig. 9a). The seasonal cycles in the T42 and T106 models are rather similar to each other and both more pronounced than in the T21 model.
CONTROL

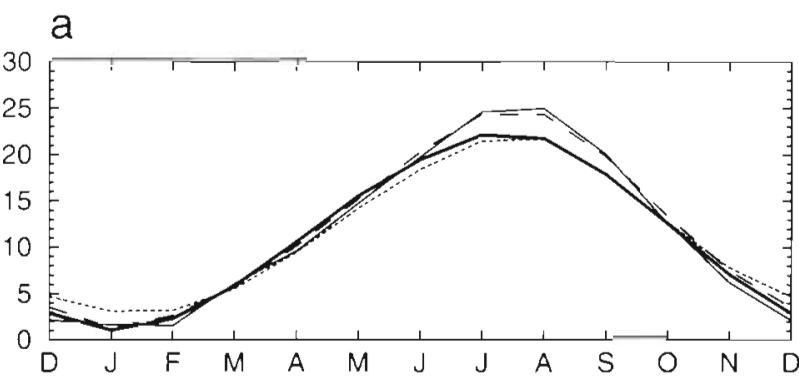

b

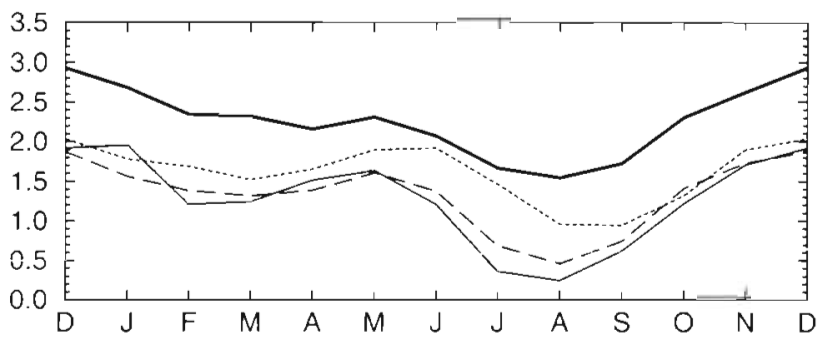

C

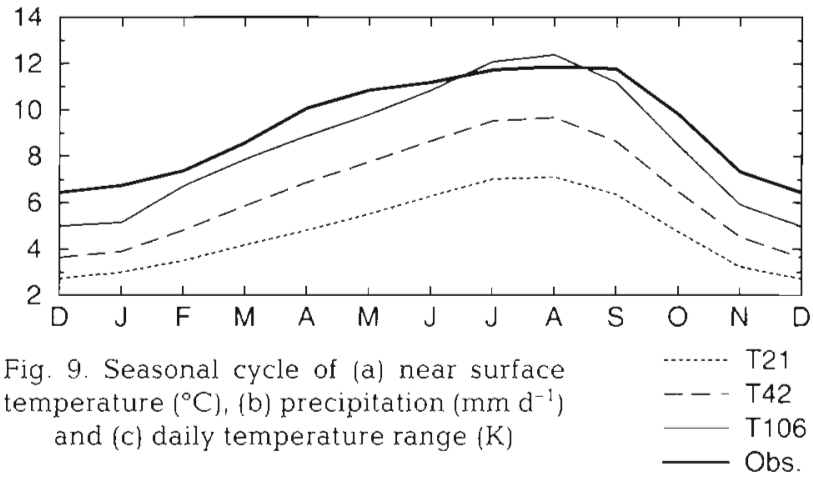

The seasonal cycle of the precipitation is simulated well with the higher resolution models, except for the almost season-independent bias of $1 \mathrm{~mm} \mathrm{~d}^{-1}$. Only the T21 shows a distortion of the seasonal cycle in summer, where there is an increase in precipitation in June, while the other models and the observations show a decrease (Fig. 9b).

While for temperature and precipitation the T42 and T106 models show similar results and only T21 behaves differently, the DTR appears to be more strongly related to the model resolution. The model with the lowest resolution exhibits the smallest range and the largest error, while the model with the highest resolution shows the highest range and the lowest error (Fig. 9c). This is, again, connected with the location of the grid points. In the low-resolution models almost all land points are situated near sea points, i.e. they exhibit maritime climate characteristics where an abundant amount of moisture is supplied by advection. In the high-resolution model, a substantial share of the 


\section{Changes (95\%-Confidence)}

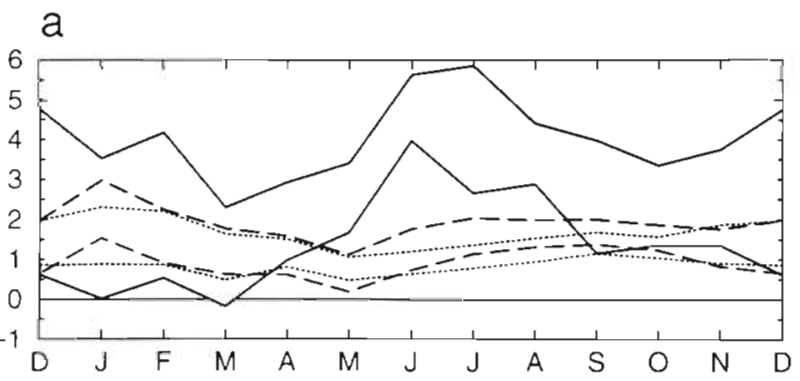

b

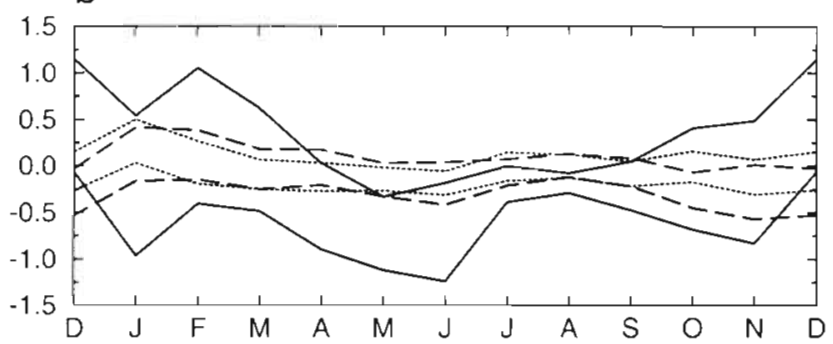

C

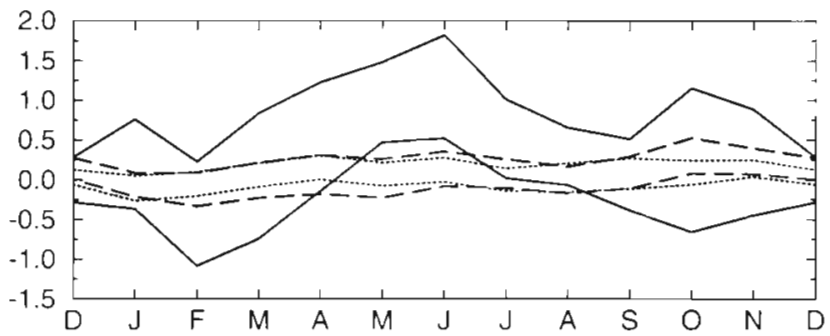

Fig. 10. Change of the seasonal cycle of (a) near surface temperature (K), (b) precipitation $\left(\mathrm{mm} \mathrm{d}^{-1}\right)$ and $(\mathrm{c})$ daily temperature range (K) for $\mathrm{CO}_{2}$ doubling

grid points are completely continental which causes the temperature and DTR to rise.

As shown in Cubasch et al. (1995a), the change of temperature induced by a doubling of the $\mathrm{CO}_{2}$ concentration in the atmosphere is small and almost independent of the season when using a T42 model. The same statement holds for the T21 resolution. The T106 experiment, however, shows a clear seasonal signal with a maximum of $5 \mathrm{~K}$ in summer. In this respect, it resembles the $\mathrm{T} 42$ simulation under $3 \times \mathrm{CO}_{2}$ conditions. This indicates that the T106 model has a higher sensitivity than the models with lower resolution (Fig. 10a).

For the precipitation change this statement can also be confirmed. Here, again, the T106 model shows a higher sensitivity than the lower resolution models which show a negligible response (Fig. 10b).

For the DTR as well, the T21 and T42 models show almost no response, while the T106 is more sensitive. Its response is even higher than for the $3 \times \mathrm{CO}_{2}$ experiment with the $\Upsilon 42$ model (Cubasch et al. 1995a), but it has the same seasonal structure (Fig. 10c). The strong seasonal response in the T106 model is caused by drying at the continental points in summer (cf. Section 4.3), particularly in the Alpine region. This leads to a stronger temperature increase during daytime, due to higher insolation and less evaporation, and to a stronger temperature decrease during nighttime, because no formation of (low) clouds inhibits the longwave radiation. Both effects add to the diurnal temperature range.

\subsection{Changes in precipitation intensity}

To estimate the change in the rain intensity, the daily data were scanned for the rain amount per $24 \mathrm{~h}$ interval, separated into classes $(>1,>2,>5,>10,>20,>50$, $>100 \mathrm{~mm} \mathrm{~d}^{-1}$ ), and then added for every season.

Fig. 11 shows the change of the precipitation classes for the control and the $2 \times \mathrm{CO}_{2}$ simulations in Southern Europe for all seasons. With the exception of the winter season, Southern Europe experiences less precipitation under increased $\mathrm{CO}_{2}$ concentration conditions. This tendency is simulated at all resolutions. The trend seems to be amplified with increased resolution. The number of days with intense rain stays about the same
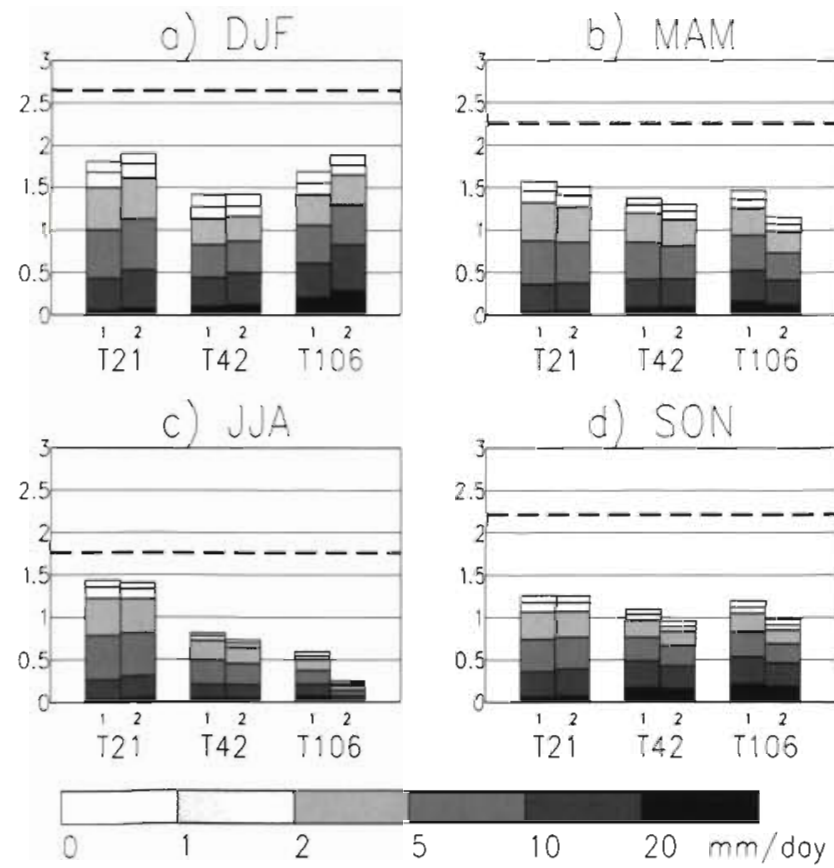

Fig. 11. Seasonal distribution of precipitation intensity for the $1 \times \mathrm{CO} 2$ and $2 \times \mathrm{CO}_{2}$ integrations for Southern Europe for the T21, T42 and T106 experiments $\left(1=\right.$ control, $\left.2=2 \times \mathrm{CO}_{2}\right)$. Height of each column indicates the total seasonal precipitation, and subdivisions the share of each precipitation class to the total amount. (a) Winter, (b) spring, (c) summer, (d) autumn. Dashed lines indicate the observed total amount 
or increases marginally at the lower resolutions, while it decreases with higher resolutions. The decrease of overall rainfall can mainly be attributed to a decrease of the weak and medium intensity classes. In winter, the precipitation increases in all resolutions. This increase is mainly caused by severe precipitation, particularly visible in the T106 model.

\subsection{Changes in the frequency of droughts}

To get a more detailed view of the frequency of consecutive dry days (precipitation $<0.1 \mathrm{~mm} \mathrm{~d}^{-1}$ ), 11 classes, depending on the number of consecutive dry days, were defined. The classes were: 1-10, 11-20, $21-30,31-60,61-90,91-120,121-150,151-180$, $180-270,270-360$, and $>360$ days without precipitation. The simulated years were scanned for these dry spells and every dry period was classified. The frequency was normalized by the total number of days analysed.

Over Southern Europe, an increase in the probability of longer dry spells is predicted by all model resolutions. In all seasons, all models simulate longer dry spells as $\mathrm{CO}_{2}$ increases; however, the T106 model tends to have more short periods of no rain than do the other resolutions (Fig. 12).
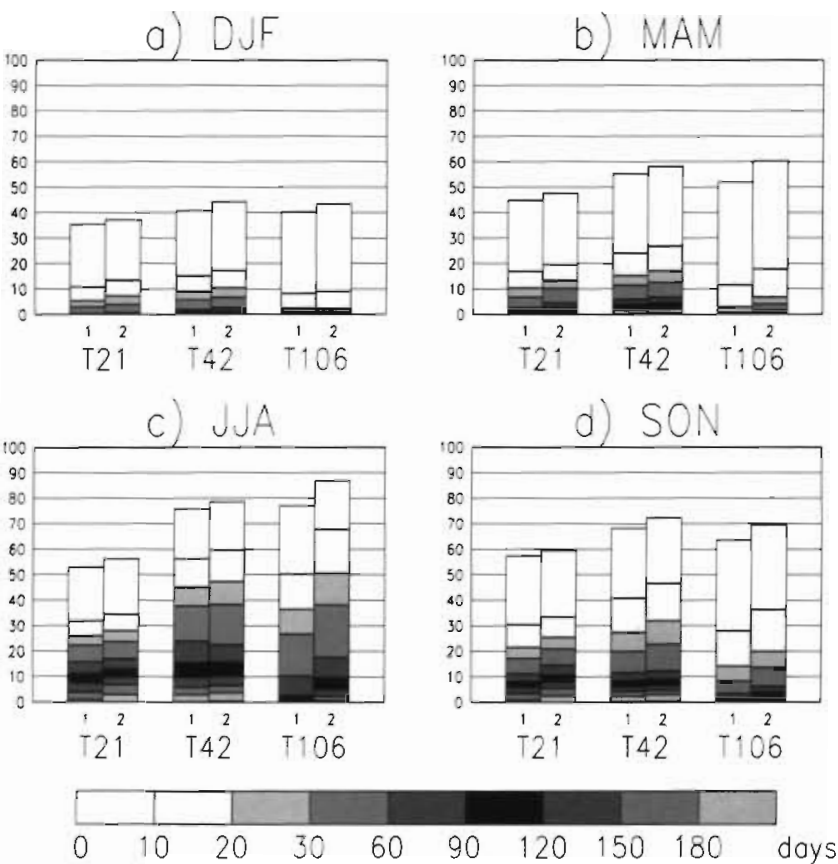

Fig. 12. Seasonal distribution of consecutive dry days for the $1 \times \mathrm{CO}_{2}$ and $2 \times \mathrm{CO}_{2}$ integration for Southern Europe $(1=\mathrm{con}-$ trol. $2=2 \times \mathrm{CO}_{2}$ ). Height of each column indicates the total percentage of dry days, and subdivisions the share of each dry spell class to the total percentage. (a) Winter, (b) spring,

(c) summer, (d) autumn

\subsection{Summary of the time-slice experiments}

The model with the highest resolution simulates the observed features better than the models with lower resolution. This can be verified objectively. For temperature, the RMS error becomes smaller with increased resolution; only for precipitation is there a trend where the RMS error increases with increased resolution. In the case of precipitation, a constant bias has to be taken into consideration (see Section 4.5). The T21 model has the lowest bias in summer (for the wrong reason, i.e. it increases precipitation in summer instead of decreasing it). The RMS verification method fails to recognize this effect and gives the lowest error, but for the wrong reason.

A comparison with the other T21 models used in the model intercomparison (cf. Section 2) shows a high correlation for temperature as well as for precipitation. In summer and in winter, the ECHAM2/OPYC simulation has much smaller RMS and anomaly correlation values for temperature than the ECHAM1/LSG simulation when compared to ECHAM3 (Table 23). For precipitation, the ECHAM2/OPYC simulation is closer to the ECHAM3 model than the ECHAM1/LSG model in every season (Table 24).

Roeckner et al. (1993) have already indicated that the ECHAM2 and the ECHAM3 models simulate large-scale flow in a similar fashion because they use a common topography and no gravity-wave drag, while the flow simulated by the ECHAM1 model is too weak across the North Atlantic. The reason for this is that the gravity-wave drag, in combination with the low resolution, slows the circulation down unrealistically.

The simulated DTR is enhanced with resolution and reaches the observed values at the highest resolution. The highest resolution model also shows the largest response to the changed climatic conditions and displays seasonal variation as well. The lower resolution models show only a marginal response. For the simulated change, the T42 model is, contrary to the simulation of the control climate, closer to the T21 model than to the T106 model. This is connected to the number of land points which are situated next to sea points. These points respond like a maritime climate with a large inertia. In the T106 model, the large number of continental land points dominates, and these respond more directly to the warming due to the enhanced greenhouse gas concentration.

\section{STATISTICAL DOWNSCALING}

A completely different method, which does not employ dynamical models, is statistical downscaling. Here we demonstrate the technique of statistical down- 
Table 23. Comparison of near surface temperature simulated by the transient experiments versus that simulated by a time-slice experiment

\begin{tabular}{|lcccc|} 
& & RMS & \multicolumn{2}{c|}{ Correlation with subtraction of mean } \\
& DJF & JJA & DJF J \\
\hline ECHAM1/LSG vs ECHAM3 time-slice & $2.6^{\circ} \mathrm{C}$ & $4.6^{\circ} \mathrm{C}$ & $92 \%$ & $86 \%$ \\
ECHAM2/OPYC vs ECHAM3 time-slice & $2.2^{\circ} \mathrm{C}$ & $1.4^{\circ} \mathrm{C}$ & $99 \%$ & $99 \%$ \\
\hline
\end{tabular}

Table 24. Comparison of precipitation simulated by transient experiments versus that simulated by a time-slice experiment

\begin{tabular}{|c|c|c|c|c|}
\hline & \multicolumn{2}{|c|}{ RMS } & \multicolumn{2}{|c|}{ Correlation with subtraction of mean } \\
\hline & DJF & JJA & DJF & JJA \\
\hline ECHAM1/LSG vs ECHAM3 time-slice & $1.1 \mathrm{~mm} \mathrm{~d}^{-1}$ & $1.2 \mathrm{~mm} \mathrm{~d}^{-1}$ & $45 \%$ & $69 \%$ \\
\hline ECHAM2/OPYC vs ECHAM3 time-slice & $0.3 \mathrm{~mm} \mathrm{~d}^{-1}$ & $0.8 \mathrm{~mm} \mathrm{~d}^{-1}$ & $95 \%$ & $95 \%$ \\
\hline
\end{tabular}

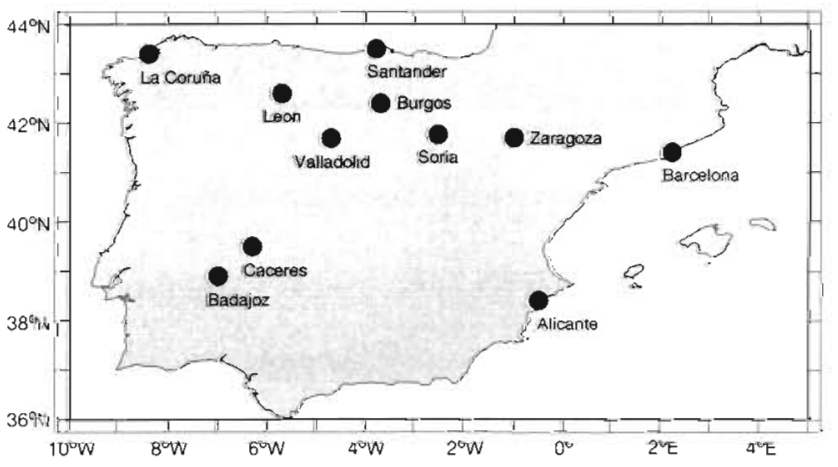

Fig. 13. Locations and names of the meteorological stations used to design a statistical downscaling model to specify daily amounts of rainfall as a function of the large-scale atmospheric state

scaling with a case study on Iberian precipitation statistics in winter (DJF). For 11 stations (see Fig. 13) daily amounts of rainfall were available from 1965 to 1985 . The data were checked visually for inhomogeneities, but no obvious problems were found. The amount of rainfall at these stations is linked to the large-scale state of the atmosphere using an analog approach (Zorita et al. 1995). For that purpose, the daily largescale atmospheric state is characterized by a vector $S(t)$ formed from the coefficients of the first 5 EOFs of the sea level pressure (SLP) field and of the $700 \mathrm{hPa}$ temperature field over the Atlantic, western Europe and northwest Africa $\left(70^{\circ}-20^{\circ} \mathrm{E}, 20^{\circ}-70^{\circ} \mathrm{N}\right)$ on 3 consecutive days $(t, t-1, t-2)$. Thus, $S(t)$ is a 30 -dimensional vector ( 2 variables $\times 5$ EOFs $\times 3$ days).

An amount of rain can be attached to any target SLP pattern $S(t)$, either observed or simulated by a GCM, by identifying the SLP pattern $S(u)$ in the pool of historical observations which comes closest to the target pattern, as follows:

$$
\|S(u)-S(t)\|=\text { minimum }
$$

The pattern $S(u)$ is called the 'analog' of $S(t)$. The amount of rainfall observed on Day ' $u$ ' may be used as an estimate of the rainfall at time $t, \hat{R}(t)$ :

$$
\hat{R}(t)=R(u)
$$

Von Storch et al. (1993) and Zorita et al. (1995) have shown that the large-scale flow of the model simulation is suitable for this downscaling method.

\subsection{Test of the method: application to observed states}

For all days in the winters from 1965 to 1985, we determined the analogs and specified the amount of rainfall according to Eq. (2). Then, we formed seasonal statistics at each of the 11 stations and compared them against the in situ observations.

First, we computed 3 numbers from the ensemble of all daily rainfall amounts that were characteristic of the distribution, namely the 10,50 and $90 \%$ percentiles. In Fig. 14, these numbers are compared with the percentiles derived from the in situ observations. There is a very good fit for all locations and for all 3 percentiles. Note that this success in reproducing the observed percentiles does not prove the skill of the technique. If the analog had been determined randomly, instead of by the minimum condition Eq. (1), the resulting distribution functions would also equal those of the in situ data.

A more conservative test can be conducted by comparing the time series of seasonal percentiles derived from the analogs and from the in situ data. Fig. 15 displays the resulting correlations of the $90 \%$ percentiles, which are reasonable for 7 of the stations. For the stations Santander, Alicante, Zaragoza and La Coruña, however, small, zero or even negative correlations are found and we have to conclude that downscaling fails for them. 

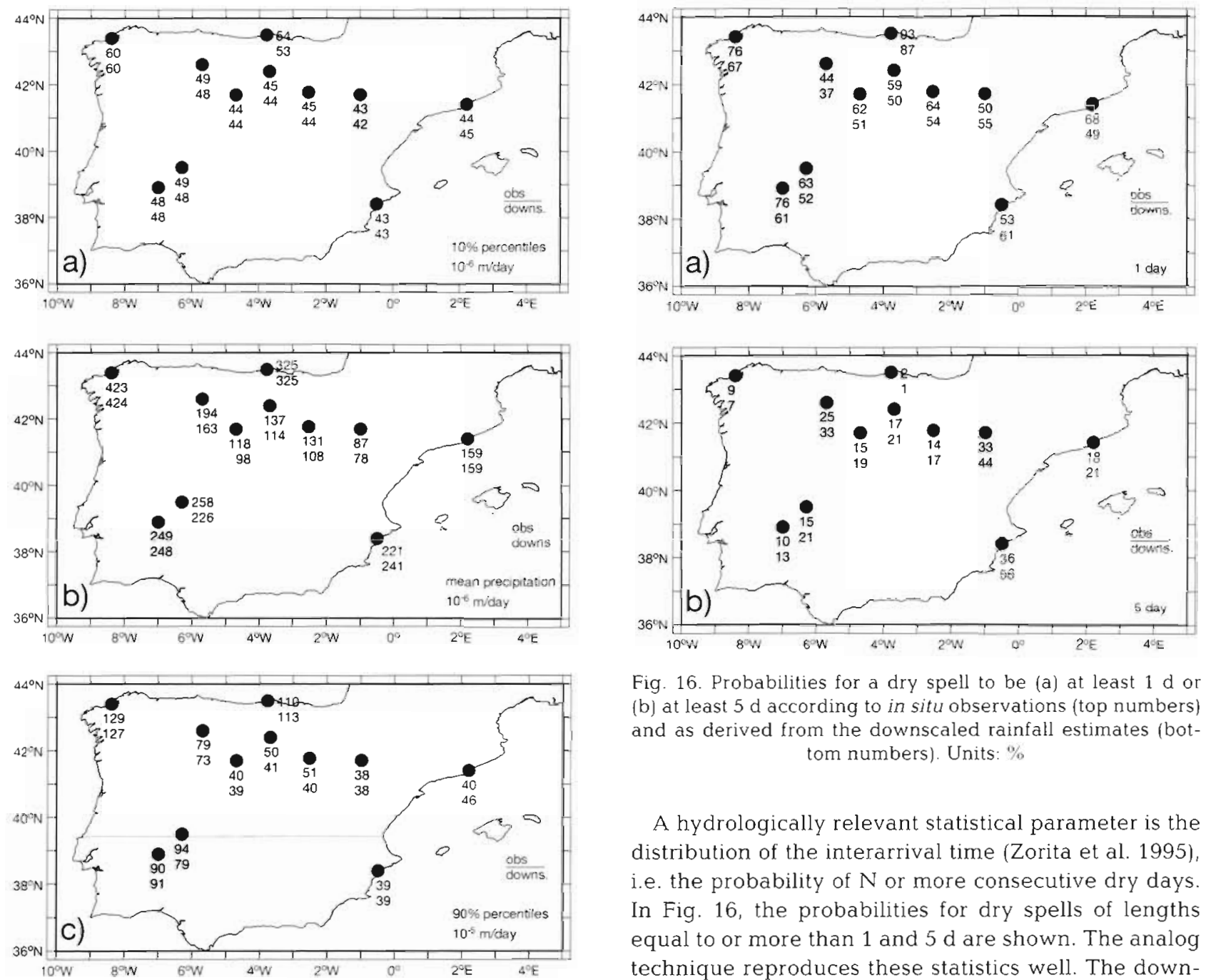

Fig. 14. Percentiles of DJF rainfall at 11 meteorological stations as derived from in situ observations (top numbers) and by the analog model from observed SLP and $700 \mathrm{hPa}$ fields (bottom numbers). Seasonal (a) 10\%, (b) $50 \%$ and (c) $90 \%$ percentiles

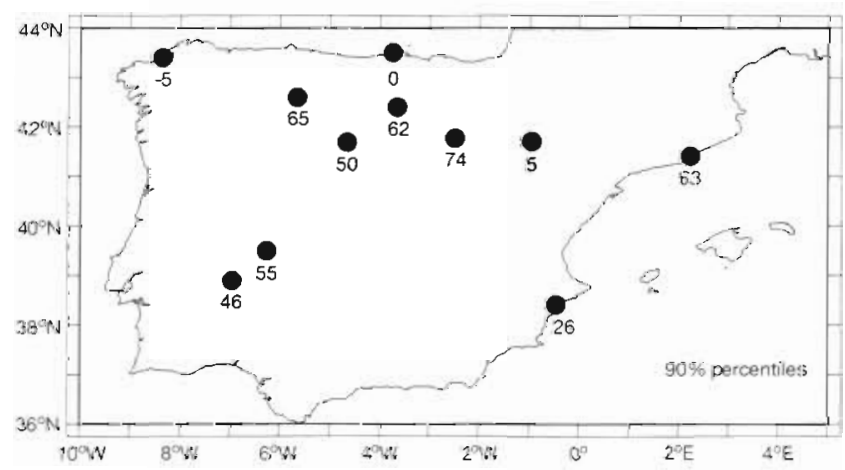

Fig. 15. Correlations of the $90 \%$ percentiles of the DJF distrbution of daily rainfall amounts as derived from in situ observations (1965-1985) by the analog model. Units: \%

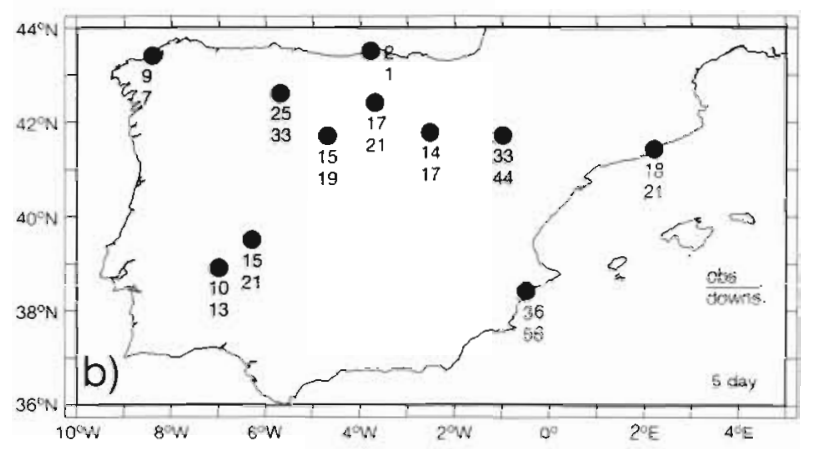

Fig. 16. Probabilities for a dry spell to be (a) at least $1 \mathrm{~d}$ or (b) at least $5 \mathrm{~d}$ according to in situ observations (top numbers) and as derived from the downscaled rainfall estimates (bottom numbers). Units: \%

A hydrologically relevant statistical parameter is the distribution of the interarrival time (Zorita et al. 1995), i.e. the probability of $\mathrm{N}$ or more consecutive dry days. In Fig. 16, the probabilities for dry spells of lengths equal to or more than 1 and $5 \mathrm{~d}$ are shown. The analog technique reproduces these statistics well. The downscaled precipitation seems to have somewhat shorter dry periods except for Alicante.

\subsection{Application of the analog model to AGCM output}

Next, we applied the analog approach to the output of the 'control' and 'scenario $A$ ' base experiments conducted with ECHAM1/LSG (cf. Table 1). Specifically, we examine the decade 2030-2040 in the scenario $A$ simulation, which covers the time of $\mathrm{CO}_{2}$ doubling in this scenario - therefore, this case is labelled ' $2 \times \mathrm{CO}_{2}$ ' This simulation was used to specify changing lower boundary conditions in the various time-slice experiments in Section 4.

Fig. $17 \mathrm{~b}$ shows the mean precipitation at 11 rain gauges downscaled from the control run (' $\left.1 \times \mathrm{CO}_{2}{ }^{\prime}\right)$ and the change derived from the ' $2 \times \mathrm{CO}_{2}$ ' time slice. Generally, the control run numbers (the upper numbers in Fig. 17) are 30 to $50 \%$ smaller than the observed averages. A similar deficit was found for the rainfall simu- 

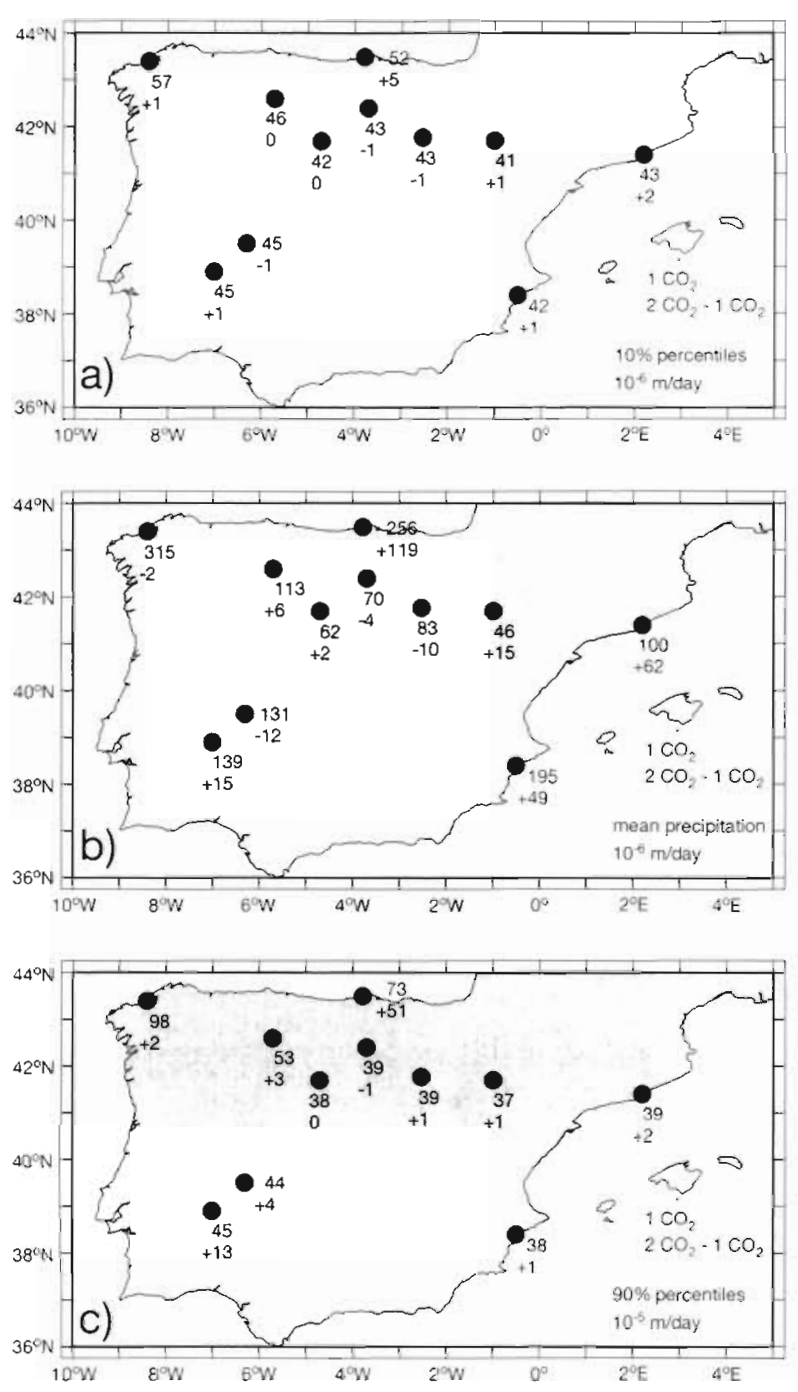

Fig. 17 Percentiles of DJF rainfall at 11 meteorological stations as derived by the analog model from output of the control run (top numbers) and from the climate change experiment (bottom numbers). Seasonal (a) 10\%, (b) $50 \%$ and (c) $90 \%$ percentiles

lated in the time-slice simulations (Fig. 7). However, the general structure is well reproduced.

The climate change, derived from the ' $2 \times \mathrm{CO}_{2}$ ' simulation by downscaling (lower numbers in Fig. 17), has a non-uniformly distributed signal. For the east coast, large increases are diagnosed (+0.5 $\left.\mathrm{mm} \mathrm{d}^{-1}\right)$, while in the inner parts both increases and decreases on the order of $0.1 \mathrm{~mm} \mathrm{~d}^{-1}$ and less are found. The large value of $+1.2 \mathrm{~mm} \mathrm{~d}^{-1}$ in Santander must be dismissed because of the lack of correlation in Fig. 15. These empirically derived data are not consistent with the T106 time-slice simulation (Fig. 7) which indicates a reduction of precipitation over the southern part of the Peninsula (of the order of $-0.2 \mathrm{~mm} \mathrm{~d}^{-1}$ ) and an increase of $+0.2 \mathrm{~mm} \mathrm{~d}^{-1}$ along the northern coast. The changes in the mean precipitation simulated by the T106 model (Fig. 7) are consistent with the simulated changes in SLP. The SLP signal $\left(2 \times \mathrm{CO}_{2}-\right.$ Control) in the North Atlantic (not shown) implies an increase of SLP over the mid Atlantic by about $1 \mathrm{hPa}$ and a small decrease over the Iberian Peninsula. This pattern would block the weather system entering the Peninsula. It also intensifies the northerly circulation, bringing more rain to the northern Iberian coast. In the ' $2 \times \mathrm{CO}_{2}$ ' experiment with the T21 model, the changes of SLP over this region are smaller and have a different sign, which explains the slight increases in estimated rainfall when the downscaling approach is applied to this low-resolution model.

Not surprisingly, the $90 \%$ percentiles derived from the GCM data substantially underestimate the observed percentiles at some locations (Fig. 17c). The $10 \%$ percentiles are rather small and therefore the observed and GCM-derived data are similar (Fig. 17a). The largest amounts of rainfall, as represented by the $90 \%$ percentiles, increase slightly at most locations; the same is true for the smallest amounts which are represented by the $10 \%$ percentiles

The distribution of the duration of dry phases is reproduced by the control run, even though the number of spells of 1 or more days' length is underrepresented (i.e. the model simulates more occasions of 2 or more consecutive rainy days) and the frequency of extended dry periods (5 or more days' length) is overestimated (Fig. 18). The effect of global warming on the distribution of the lengths of dry spells is that the number of dry spells is enhanced, but the number of extended dry periods is reduced at some locations by as much as $5 \%$ (in the northeast), while in other areas the estimate varies by $\pm 2 \%$.

\section{DISCUSSION}

A comparison of 5 different transient model simulations with coupled ocean-atmosphere low-resolution GCMs shows that directly interpolated regional climate simulations are poor. The climate change predicted by the 5 models is inconsistent and gives no clear result. This method, in connection with coarseresolution models, therefore proves to be of limited use for a regional climate assessment.

The time-slice simulations have some success in reproducing the observed temperature and simulating a consistent temperature change, but do not simulate the precipitation well. Generally, there is a tendency for improvement in the simulations with increased resolution, which is in most cases significant at the $95 \%$ level when going from $\mathrm{T} 21$ to any higher resolution. It is interesting to note that the response to changed global 

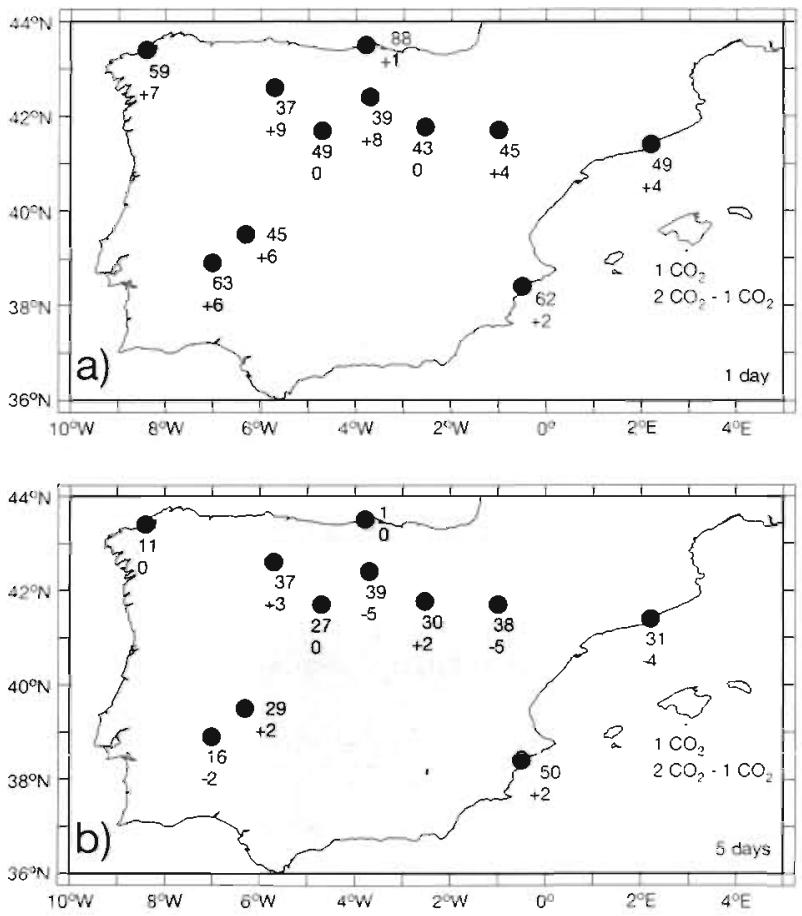

Fig. 18. Probabilities for a dry spell to be (a) at least $1 \mathrm{~d}$ or (b) at least $5 \mathrm{~d}$, as derived from the rainfall estimates downscaled from the GCM large-scale state in the control run (top numbers) and from the climate change scenario (bottom numbers). Units: \%

climate conditions is higher in the T106 than in the lower resolutions. The simulation of the annual cycle of the daily temperature range improves with increasing resolution.

Similar to that for temperature, the response of the daily temperature range to the changed climate conditions increases with resolution. In the low-resolution models most of the land grid points are adjacent to sea grid points. Therefore, their response is like that which would be expected in a maritime climate: the temperature range and the response to external forcing are damped, while the high-resolution model has a more continental character, i.e. it responds faster to internal and external changes.

The climate change signal for the severity of rain or the persistence of drought shows a resolution-independent trend, however, its amplitude is resolution dependent.

The area analyzed here is a very structured region with a lot of land and sea areas. Due to the impact that the distribution of land and sea and its representation in the model have on the result, it is difficult to transfer the findings reached in this paper to other regions where the balance between maritime points and continental points is different for the different resolutions.
The statistical downscaling method provides an inexpensive tool for the assessment of regional climate as a function of global-scale circulation. However, it can only give information about quantities for which an observational record of considerable length is available.

A comparison of the time-slice and the statistical downscaling methods shows different regional climate change patterns at the time of $\mathrm{CO}_{2}$ doubling: the statistical model yields a spatially structured pattern, with positive as well as negative signs of change in the central part of Spain (Fig. 17b), whereas the dynamical model generates a spatially homogeneous distribution (Fig. 7). At this time, we do not know which model is right. It could be that the statistical model suffers from too much noise, or that it better reflects the different influences of local features such as land use and orography. On the other hand, it might be that the T106 resolution is still too coarse to resolve the small-scale climate changes predicted by the statistical model. Simulations with higher resolution using a global model are currently impossible due to their high computing time demands. This phenomenon will therefore be analyzed in a separate study using a nested regional model. Both the statistical and the dynamical models indicate that the length of dry spells will slightly increase in a changed climate.

It has to be mentioned that the time-slice experiments are based on transient simulations where only the $\mathrm{CO}_{2}$ concentration has been increased. More recent studies by Mitchell et al. (1995) and Cubasch (1995), where the direct effect of aerosols was also taken into consideration, show that among other things, the rainfall pattern in Southern Europe is strongly affected by this additional forcing. The timeslice experiments have, therefore, to be repeated based on these new integrations. Judging by the tran-' sient simulations, the difference between the statistically and the dynamically derived rainfall change, mentioned above, cannot be explained by the addition of the sulphate aerosol effect, but rather seems to be due to topographical features.

Acknowledgements. We thank Arno Hellbach and Peter Lenzen for their support in the practical aspects of this work. Jan Perlwitz ran the time-slice experiments. The authors thank NCAR, GFDL and the Hadley Centre for making simulation data available. The research was supported by the German Ministry for Education, Science, Research and Technology (BMBF), the Max-Planck-Gesellschaft, the Freie und Hansestadt Hamburg and the EC Environmental program (EV5V-CT92-0123). The Swiss Climate program provided computing time to carry out the T106 time-slice simulations. The authors are grateful to the staff of the DKRZ for their technical support. Part of this paper was written during a visit by one of the authors (U.C.) to NCAR. 


\section{LITERATURE CITED}

Arpe K, Bengtsson L, Dümenil L, Roeckner E (1994) The hydrological cycle in the ECHAM3 simulations of the atmospheric circulation. In: Desbois M, Desalmond F (eds) Global precipitation and climate change. NATO ASI Series, Vol I, 26:361-377

Bardossy A, Plate EJ (1991) Space time modeling for daily raintall using atmospheric circulation patterns. Water Resour Res 28:1247-1259

Bengtsson L, Arpe K, Roeckner E, Schulzwelda U (1994) Climate: predictability experiments with a general circulation model. Report No. 145, Max-Planck-Institut für Meteorologie, Hamburg

Bengtsson L, Botzet M, Esch M (1994) Will greenhouse gasinduced warming over the next 50 years lead to higher frequency and greater intensity of hurricanes? Report No. 139, Max-Planck-Institut für Meteorologie, Hamburg

Cubasch U (1995) Die Vorhersage und der Nachweis der anthropogenen Klimaänderung. Ann Meteorol 31:5-8

Cubasch U, Hasselmann K, Höck H, Maier-Reimer E, Mikolajewicz U, Santer BD, Sausen R (1992) Time-dependent greenhouse warming computations with a coupled oceanatmosphere model. Clim Dyn 8:55-69

Cubasch U, Santer BD, Hegerl G (1995b) Klimamodelle-wo stehen wir? Phys Bl 51:269-276

Cubasch U, Waszkewitz J, Hegerl G, Perlwitz J (1995a) Regional climate changes as simulated in time-slice experiments. Clim Change 31:273-304

DKRZ (1993) The ECHAM3 atmospheric general circulation model. Tech Rep No. 6, DKRZ, Hamburg

Frey-Buness F, Heimann D, Sausen R (1995) A statisticaldynamical downscaling procedure for global climate simulations. Theor Appl Clim 50:117-131

Gates L, Cubasch U, Meehl GA, Mitchell JFB, Stouffer RJ (1993) An intercomparison of the control climates simulated by coupled atmosphere-ocean general circulation models. SGCCM, WCRP-82, WMO/TD No. 574

Giorgi $F(1990)$ On the simulation of regional climate using a limited area model nested in a general circulation model. J Clim 3:941-963

Giorgi F, Mearns L (1991) Approaches to the simulation of regional chmate change: a review. J Geophys Res 29: $191-216$

Gleckler PJ, Randall DA, Boer G, Colman R, Dix M, Galin V, Helfand M, Kiehl J, Kitoh A, Lau W, Liang XZ, Lykossov V, McAvaney B. Miyakoda K, Planton S (1994) Cloud-radiative effects on implied oceanic energy transports as simulated by atmospheric general circulation models. PCMDI Report No. 15, LLNL, Livermore, CA

Grotch SL, McCracken MC (1991) The use of general circulation models to predict regional climate change. J Clim 4 : 286-303

Gyalistras D, von Storch H, Fischlin A, Beniston M (1994) Linking GCM simulated climatic changes to ecosystem models. Case studies of statistical downscaling in the Alps Clim Res 4:167-189

Editor: H. von Storch, Geesthacht, Germany
Hewitson BC, Crane RG (1992) Regional-scale climate prediction from the GISS GCM. Paleogeog Paleoclim Paleoecol 97:249-267

IPCC (1990) Climate change: the IPCC scientific assessment. Houghton J, Jenkins GJ, Ephraums JJ (eds) Cambridge University Press, Cambridge

IPCC (1992) Climate change: the supplementary report to the IPCC sclentific assessment. Houghton J. Callendar BA, Varney SK (eds) Cambridge Unversity Press. Cambridge

Legates DR, Willmott CJ (1990) Mean seasonal and spatial variability un gauge corrected global precipitation. J Climatol 10:111-127

Machenhauer $B$, Windelband $M$, Botzet $M$, Jones RG, Deque $M$ (1996) Validation and intercomparison of present-day regional climate simulations over Europe: nested LAM and variable resolution global model simulations with observed or mixed layer ocean boundary conditions. Report No. 191, Max-Planck-Institut für Meteorologie, Hamburg

Mahfouf JF, Cariolle D, Royer JF, Geleyn JF, Timbal B (1994) Responses of the Meteo-France climate model to changes in $\mathrm{CO}_{2}$ and sea surface temperature. Clim Dyn 9:345-362

Matyasovzky l, Bogardi I, Bardossy A, Duckstein L (1995) Local temperature estimation under climate change. Theor Appl Clim 50:1-14

May W, Shea DJ, Madden RA (1992) The annual variation of surface temperatures over the world. NCAR Tech Note TN-372+STR, NCAR, Boulder, CO

Mearns LO, Giorgi F, Mcdaniel L, Shields C (1995) Analysis of variability and diunrnal range of daily temperature in a nested regional climate model: comparison with observations and doubled $\mathrm{CO}_{2}$ results. Clim Dyn 11:193-209

Mitchell JFB, Johns TC, Gregory JM, Tett SBF (1995) Climate response to increasing levels of greenhouse gases and sulphate aerosols. Nature 376:501-504

Roeckner E, Arpe K, Bengtsson L, Brinkop S, Dümenil L, Esch $M$, Kirk E, Lunkeit F, Ponater M, Rockel B, Sausen R, Schlese U, Schubert S, Windelband M (1992) Simulation of the present-day climate with the ECHAM model: impact of model physics and resolution. Report No. 93, Max-Planck-Institut für Meteorologie, Hamburg

von Storch H (1995) Inconsistencies at the interface of climate impact studies and global climate research. Meteorol Z (NF) 4:72-80

von Storch H, Zorita E, Cubasch U (1993) Downscaling of global climate change estimates to regional scales: an application to Iberian rainfall in wintertime. J Clim 6 : $1161-1171$

Waszkewitz J (1996) High resolution versus long simulation Report, Max-Planck-Institut für Meteorologie, Hamburg

Wigley TML, Jones PD, Briffa KR, Smith G (1990) Obtaining subgrid scale information from coarse-resolution general circulation model output. J Geophys Res 95:1943-1953

Zorita E, Hughes J, Lettenmaier D, von Storch H (1995) Stochastic characterisation of regional circulation patterns for climate model diagnosis and estimation of local precipitation. J Clim 8:1023-1042

Manuscript first received: January 10, 1996

Revised version accepted: August 7, 1996 